\title{
Indicador sintético de capital intelectual: humano y estructural. Un factor de competitividad ${ }^{* * *}$
}

\begin{abstract}
The measurement of intangibles in the business sector brings together experiences that use synthetic indicator models, with subjective information linked to traditional accounting and information systems. Along these same lines, we provide a response to the needs of the new macroeconomy, building an indicator that is a combination of the classic data base and the data created ad hoc to deal with the challenges of the knowledge-based economy, and that in turn is a reference for competitiveness between economic spaces. We researched the method and the quantification of a regional indicator of intellectual capital, disaggregating into human and structural factors. Later we introduced a comparative analysis for the regions of the EU-15, examining opportunities for growth, also the correlation of production variables. Development perspectives should promote knowledge, through R\&D, with the guarantee and support of a motivated, well-trained labour market.
\end{abstract}

Keywords: intangible, intellectual capital, indicator, competitiveness, new economy.

\section{Resumen}

La medición de intangibles en el ámbito empresarial acumula experiencias que utilizan modelos de indicadores sintéticos, con información subjetiva unida a los sistemas de información contable tradicionales. En esta línea, damos respuesta a las necesidades de la nueva macroeconomía, construyendo un indicador combinación de las bases de datos clásicas y los datos creados 'ad hoc' para afrontar los retos de la economía del conocimiento, permitiendo actuar como referente de competitividad entre espacios económicos. Así, estudiamos el método y cuantificación del indicador regional de capital intelectual, desagregado en factor humano y estructural. Introducimos, posteriormente, un análisis comparado para las regiones de la UE-15, examinando sus oportunidades de crecimiento, así como la correlación con variables de producción. Las perspectivas de desarrollo deben apostar por el conocimiento, a través de la $\mathrm{I}+\mathrm{D}$, con la garantía y soporte de un mercado laboral motivado y formado.

Palabras clave: intangible, capital intelectual, indicador, competitividad, nueva economía. 


\section{Introducción}

$\mathrm{E}$ $\mathrm{n}$ los últimos años, los activos intangibles constituyen uno de los principales factores del éxito presente y futuro de las empresas, incrementándose cada vez más las inversiones en los mismos. Hoy en día, tener unas instalaciones modernas no garantiza a las entidades una posición competitiva en los mercados, puesto que es necesario contar, además, con procesos de innovación permanente, disponer de un personal con las competencias adecuadas al puesto de trabajo, poseer una fidelidad de los clientes, la capacidad de liderazgo, las relaciones entre trabajadores, la credibilidad de los directivos, habilidad para retener y atraer los mejores profesionales, etc. En definitiva, el desarrollo de todo un conjunto de atributos de carácter intangible se está convirtiendo en uno de los soportes básicos de las empresas, al encontrarse, éstas inmersas en una economía cuya piedra angular viene constituida por el conocimiento, como único medio de competir en un mundo cada vez más globalizado. De igual modo, por extensión, un valor de producción mayor para un área geográfica, no garantiza excelentes resultados a futuro, ni tan siquiera su competitividad, precisará también valores adecuados en factores intangibles, que garanticen, a medio y largo plazo, esa ganancia.

Así, los cambios que se están produciendo en la economía mundial conducen a la consideración del conocimiento como un elemento fundamental de la escena económica, de ahí que no es extraño, que tanto los diferentes niveles de administración como las propias empresas se encuentren interesa-

Prof. Dr. D. Árr. D. Área de Econometría, Facultad de Ciencias Económicas y Empresariales de Albacete, Universidad de Castilla La Mancha, España. E-mail: victor. lopez@uclm.es.

** Prof. Dr. D. Área de Economía Financiera y Contabilidad, Facultad de Derecho y Ciencias Sociales de Ciudad Real, Universidad de Castilla La Mancha, España. Email: domingo.nevado@uclm.es

*** Prof. Dr. D. Área Economía Regional y Economía del Sector Público, Facultad de Ciencias Económicas y Empresariales de Albacete, Universidad de Castilla La Mancha, España. E-mail: jose.banos@uclm.es.

**** Códigos JEL: R11, O47.

Recibido el 20 de julio de 2006

Aceptado el 29 de marzo de 2007 dos en definir, medir, valorar, controlar y gestionar el factor intelectual.

En este sentido, se han realizado distintas propuestas de medición y gestión del capital intelectual para una firma (Kaplan y Norton, 2001; Lev, 2001), entendiendo que la posible diferencia entre el valor de mercado y el contable es debida a este agregado de intangibles. Los modelos pasan por definir una serie de grupos que conforman este capital intelectual y el establecimiento de indicadores para su valoración.

De forma paralela a estos procesos, hemos de considerar el hecho, nada desdeñable, de que en el mundo, en general, y en los países de nuestro entorno, en particular, han tomado y lo continúan haciendo, mayor relevancia, los espacios regionales e incluso locales. Cada vez, son estos niveles los que demandan mayor autonomía para tomar las decisiones que, a su juicio, consideran más apropiadas para conseguir un cierto éxito en el desarrollo y crecimiento económico, acompañados de los procesos sociales de 'glocalización' que propone Robertson (2000).

Las regiones, cada vez con mayor énfasis, pretenden ser las autoras principales en el diseño de políticas y actuaciones para conseguir un mayor desarrollo, que les permita converger con otras unidades territoriales con mayores y mejores capacidades. Este hecho es aún más importante, si cabe, si se toman en consideración los numerosos espacios regionales e intrarregionales que quedan al margen de los circuitos a través de los cuales se produce la mayor cantidad de movimientos de mercancías y conocimiento y, en consecuencia, del ansiado crecimiento y bienestar.

En este contexto, estos espacios están sufriendo numerosas transformaciones como consecuencia de diversos factores: económicos, sociales, demográficos, político-administrativos, y así seguirán en el futuro. Se trata, en definitiva, de la falta de adaptación a las nuevas tecnologías, planteando, en muchos casos, estrategias pasivas de carácter defensivo, que justifican, a veces, la existencia de economías sumergidas. Si a ello se une que en muchos de estos municipios o regiones la pérdida de población es significativa, por estar anclados, entre otras cuestiones, en una estructura económi- 
ca relativamente agraria, el panorama se muestra desalentador.

Por estos y otros motivos es por lo que se les viene prestando una especial atención por parte de diferentes colectivos, políticos e intelectuales, de distintos campos científicos, geográficos, políticos, sociológicos, económicos, etc., siendo necesario atender las numerosas perspectivas que interceden en los diferentes procesos de desarrollo.

En la actualidad, estos espacios regionales deben abordar de manera imperiosa los aspectos relativos a la innovación, investigación y desarrollo, es decir, a la gestión del conocimiento, ventaja competitiva que radica en el conocimiento disponible en la región, cómo se encuentra estructurado, con qué infraestructura se cuenta, de qué financiación se dispone, etc.

Partiendo de esta realidad, tras una revisión de los trabajos especializados, extenderemos la medida de capital intelectual para una sola empresa hacia la medición de los intangibles para un ámbito territorial. En ese proceso consideramos su cálculo para un conjunto de empresas de un área geográfica determinada, esto es un enfoque mesoeconómico que permitirá una valoración más precisa de su posición económica y potencial, en relación con la reflejada en las medidas oficiales del ingreso regional.

La medición del capital intelectual para un espacio económico específico supondría contar con un elemento adicional para explicar la generación de riqueza y justificar las diferencias presentes entre territorios. En este sentido, los modelos actuales se encuentran limitados, ya que la clásica función de producción tipo Cobb-Douglas no incluye el conocimiento como una variable determinante en el crecimiento y desarrollo de la economía. El modelo que aquí se presenta permite el desarrollo de un nuevo sistema de información, así como la valoración de la contribución de los recursos intangibles a la riqueza de un área. Para ello, se derivan un grupo de indicadores que permiten emprender un análisis comparativo entre regiones o, incluso, sectores. Con esta forma de proceder probablemente se detectarán mayores diferencias entre las regiones, trabajando bajo la hipótesis de que las más ricas son las más intensivas en capital intelectual.

\section{La medición de capital intelectual desde una perspectiva macro: estudios previos}

En lo que se refiere al estudio y análisis del proceso de medición y valoración de los intangibles es preciso mencionar que se trata de una materia novel, que se encuentra en una fase incipiente, en especial, en el ámbito que se empieza a conocer como el Capital Intelectual de las Naciones (Amidon, 2001; MAP, 2002). Se pone de manifiesto, en esta situación, la importancia que adquieren el clima de innovación y los procesos de transferencia tecnológica. Estos son fundamentales para articular el modelo de capital intelectual y su sistema de relaciones, conocido su soporte en la creación e intercambio de información y conocimiento en las diferentes esferas socio-económicas. El resultado es un conjunto de regiones o naciones con capacidad para generar valor y bienestar social en economías desarrolladas, en la línea de las "naciones inteligentes" (Quinn, 1992).

Ahora bien, antes de abordar la perspectiva del Capital Intelectual de las Naciones, es necesario poner de manifiesto cuál es el estado actual de los conocimientos. Partimos de los modelos de capital intelectual utilizados, los cuales están siendo destinados tanto a la mejora de la gestión empresarial como hacia la construcción de modelos macro para espacios nacionales, regionales o locales.

Existen diferentes clasificaciones de los modelos de capital intelectual. Sería complicado y desacertado decantarnos por una de ellas; además, no es el objetivo de este artículo. Pero podemos decir de las mismas, como comenta Castilla (2006), que van dirigidas a responder a tres aspectos: ¿para qué?, distinguimos entonces modelos para la gestión o la revelación; ¿qué? modelos globales e individuales, y ¿cómo? modelos monetarios y no monetarios. De esta forma, presentamos una posible clasificación de estos modelos distinguiendo entre:

1. Modelos conceptuales (cuadro 1). Aquellos que han sido origen posterior de los modelos globales o individuales. 
2. Modelos globales o individuales (cuadros 2 y 3). En función de que los mismos estimen un valor de todos los intangibles de una organización o bien información detallada de cada uno de ellos.

Como se puede observar (cuadros 1, 2 y 3 ), las investigaciones previas realizadas se han centrado en poner de manifiesto la importancia de los intangibles en las organizaciones y la necesidad de establecer instrumentos para medirlos. Así, han conseguido desarrollar y constatar:

- Ventajas sobre la disposición de información sobre intangibles a nivel de decisión y de imagen corporativa.

- Los procesos de gestión de intangibles para la creación de valor y determinación de su estructura llegando en su definición a la máxima eficiencia.
- Definición y clasificación de intangibles, así como la evidencia del hecho diferencial según el sector al que pertenezca la companía.

- La necesidad de presentar informes de capital intelectual por las empresas y el modo, no tanto la forma, en que este informe debe presentarse.

Pero en líneas generales, no hay un consenso en todos los aspectos, aunque se obtienen determinados acuerdos, como ahora pondremos de manifiesto. Una vez analizados los modelos y comentado los principales grupos de investigación dentro del ámbito empresarial, nos vamos a referir al ámbito macro, esto es, el capital intelectual de las naciones o, generalizando, el capital intelectual territorial, si atendemos a los procesos de centralización o descentralización que se vienen

Cuadro 1. Modelos conceptuales

\begin{tabular}{|c|c|c|c|}
\hline $\begin{array}{l}\text { Tjänesteförbundet, } \\
1993 .\end{array}$ & $\begin{array}{l}\text { Análisis de los intangibles } \\
\text { mediante tres capitales: clientes, } \\
\text { humano y estructural. Son } \\
\text { medidos mediante indicadores } \\
\text { no financieros. }\end{array}$ & $\begin{array}{l}\text { Primer modelo que distingue } \\
\text { entre capitales individuales y } \\
\text { estructurales. }\end{array}$ & $\begin{array}{l}\text { No está suficientemente } \\
\text { desarrollado. }\end{array}$ \\
\hline $\begin{array}{l}\text { Balance Invisible } \\
\text { (Arbetsgruppen, 1998; } \\
\text { y Sveiby, 1997). }\end{array}$ & $\begin{array}{l}\text { Presenta un balance que recoja } \\
\text { el capital intelectual, lo divide } \\
\text { en individual y estructural. El } \\
\text { primero se refiere a los individuos } \\
\text { y el segundo a los procedimientos } \\
\text { y sistemas de la organización. }\end{array}$ & $\begin{array}{l}\text { Modelo de referencia para el } \\
\text { desarrollo de estados de Capital } \\
\text { Intelectual. Flexibilidad, } \\
\text { elementos intangibles específicos } \\
\text { para cada organización. }\end{array}$ & $\begin{array}{l}\text { Falta de desarrollo de indicadores } \\
\text { propuestos. }\end{array}$ \\
\hline $\begin{array}{l}\text { Ratio: valor contable } \\
\text { / valor mercado }\end{array}$ & $\begin{array}{l}\text { Determina la relación y diferencia } \\
\text { entre el valor de mercado y valor } \\
\text { contable. }\end{array}$ & $\begin{array}{l}\text { Modelo sencillo y rápido como } \\
\text { primera aproximación al valor de } \\
\text { intangibles. }\end{array}$ & $\begin{array}{l}\text { Heterogeneidad de los criterios } \\
\text { empleados, factores exógenos y } \\
\text { los problemas de los ajustes a } \\
\text { valores contables. }\end{array}$ \\
\hline Q de Tobin & $\begin{array}{l}\text { Compara el valor de mercado } \\
\text { de un bien con su coste de } \\
\text { reposición. }\end{array}$ & $\begin{array}{l}\text { Análisis de tendencias del Capital } \\
\text { Intelectual. }\end{array}$ & $\begin{array}{l}\text { Efectos de variables exógenas. } \\
\text { Los derivados de valores } \\
\text { contables. }\end{array}$ \\
\hline $\begin{array}{l}\text { Valor intangible } \\
\text { calculado }\end{array}$ & $\begin{array}{l}\text { Considera que el valor de los } \\
\text { bienes intangibles es igual a la } \\
\text { capacidad de una empresa para } \\
\text { superar al competidor medio que } \\
\text { posee bienes tangibles similares. } \\
\text { Cálculo del ROA (ratio de } \\
\text { rentabilidad de activos) }\end{array}$ & $\begin{array}{l}\text { Permite comparaciones entre } \\
\text { industrias y dentro de éstas. }\end{array}$ & $\begin{array}{l}\text { El problema asociado al uso de } \\
\text { medias. No aplicable a sectores } \\
\text { dominados por pequeñas } \\
\text { empresas. El mantenimiento } \\
\text { futuro de los superbeneficios. }\end{array}$ \\
\hline
\end{tabular}

Fuente. Elaboración propia. 
Cuadro 2. Modelos globales

\begin{tabular}{|c|c|c|c|}
\hline MODELO & TÉCNICA & FORTALEZA & DEBILIDAD \\
\hline $\begin{array}{l}\text { Capital del conocimiento (Lev, } \\
\text { 2001). }\end{array}$ & $\begin{array}{l}\text { Estimación de las ganancias } \\
\text { normales de una entidad } \\
\text { minoradas por la contribución } \\
\text { de los recursos físicos y } \\
\text { financieros y descontadas al } \\
\text { momento actual. }\end{array}$ & $\begin{array}{l}\text { Una estimación más real del } \\
\text { Capital Intelectual que la } \\
\text { generada por la diferencia } \\
\text { entre valor contable y de } \\
\text { mercado. }\end{array}$ & $\begin{array}{l}\text { Subjetividad de la estimación } \\
\text { de las tasas de ganancias } \\
\text { medias. No considera sinergias } \\
\text { entre recursos tangibles e } \\
\text { intangibles. }\end{array}$ \\
\hline $\begin{array}{l}\text { Coeficiente de eficiencia } \\
\text { (Edvinson y Malone, 1999). }\end{array}$ & $\begin{array}{l}\text { Establecimiento de un capital } \\
\text { intelectual como suma de } \\
\text { capitales, obtenidos estos por } \\
\text { el producto de indicadores } \\
\text { monetarios corregidos por } \\
\text { indicadores de eficiencia. }\end{array}$ & $\begin{array}{l}\text { Carácter integral, contando } \\
\text { con una perspectiva financiera } \\
\text { y otras complementarias que, } \\
\text { combinadas, permiten estimar } \\
\text { el valor de mercado de la } \\
\text { empresa }\end{array}$ & $\begin{array}{l}\text { Los fundamentos teóricos } \\
\text { del Capital Intelectual } \\
\text { como diferencia entre valor } \\
\text { de mercado y contable. No } \\
\text { considera otras variables } \\
\text { explicativas. }\end{array}$ \\
\hline $\begin{array}{l}\text { Valoración y gestión (Nevado } \\
\text { y López, 2000). }\end{array}$ & $\begin{array}{l}\text { Estimación de un modelo de } \\
\text { valoración y gestión mediante } \\
\text { modelos estocásticos. } \\
\text { Distingue un capital } \\
\text { intelectual explicitado frente } \\
\text { al no explicitado. }\end{array}$ & $\begin{array}{l}\text { Valoración y gestión del capital } \\
\text { intelectual. Predicción de } \\
\text { estrategias. }\end{array}$ & $\begin{array}{l}\text { Requerimientos y elaboración } \\
\text { de información de bastantes } \\
\text { períodos. }\end{array}$ \\
\hline $\begin{array}{l}\text { Modelo Nova (Camisón, } \\
\text { Palacios y Devece, 2000). }\end{array}$ & $\begin{array}{l}\text { Cálculo de la diferencia } \\
\text { entre la situación del Capital } \\
\text { Intelectual en dos períodos } \\
\text { diferentes y el efecto recíproco } \\
\text { de cada bloque. }\end{array}$ & $\begin{array}{l}\text { Comparaciones globales } \\
\text { del Capital Intelectual } \\
\text { que permiten una primera } \\
\text { aproximación a su valor. }\end{array}$ & $\begin{array}{l}\text { El modelo estático que se } \\
\text { centra solamente en dos } \\
\text { períodos. }\end{array}$ \\
\hline $\begin{array}{l}\text { Índice del Capital Intelectual } \\
\text { (Roos, 2001). }\end{array}$ & $\begin{array}{l}\text { Capital Intelectual es el } \\
\text { humano (competencia, } \\
\text { actitud, agilidad intelectual) } \\
\text { y estructural (relaciones, } \\
\text { organización y renovación- } \\
\text { desarrollo). }\end{array}$ & $\begin{array}{l}\text { Acercamiento a un valor } \\
\text { intangible y análisis de sus } \\
\text { fluctuaciones entre períodos. }\end{array}$ & $\begin{array}{l}\text { Dificultad de homogeneizar } \\
\text { medidas diferentes en una } \\
\text { magnitud resumen.Falta } \\
\text { de instrucciones para su } \\
\text { elaboración. }\end{array}$ \\
\hline
\end{tabular}

Fuente. Elaboración propia.

produciendo en diferentes áreas mundiales. A este respecto, hay que decir que el estado actual de los conocimientos se encuentra en una fase embrionaria, donde no existen unas metodologías contrastadas y generalmente aceptadas. La mayor parte de las propuestas existentes están limitadas a una recopilación sistemática de datos sin un marco de referencia comparativo. De facto, tal como apuntan Dalmau y Baixauli (2005), gran parte de los modelos sobre capital intelectual en las regiones surgen como extrapolación de los modelos de capital intelectual en las empresas. Podemos, así, argumentar la conexión existente entre las aplicaciones al mundo empresarial y las que se realizan en el ámbito territorial.

De manera previa a relacionar diferentes investigaciones que sobre marcos territoriales concretos se han desarrollado, conviene tomar en consideración alguna de las matizaciones que deberían tenerse en cuenta al referirnos a la medición del capital intelectual de las regiones y, por extensión, de los países. Parece evidente, tal como se afirma en Sánchez Medina (2004), que la relevancia del capital intelectual va más allá del ámbito empresarial, constituyendo hoy día un activo de enorme trascendencia para los territorios. Referirnos a variables tales como el crecimiento económico, la competitividad o el propio desarrollo implica una significación relativa a una contextualización macro, donde las ideas y el know how juegan un papel fundamental para la consecución de los citados objetivos (Bradley, 1997a, b). Plantea este autor que aquellas empresas y países que se demoren en la práctica organizacional corren un serio peligro de quedar aisladas y atrasadas. Distingue entre capital intelectual y humano, defendiendo la supremacía del primero sobre el segundo, en el crecimiento económico, la creación de riqueza y la ventaja sobre los competidores. Una nota impor- 
Cuadro 3. Modelos individuales

\begin{tabular}{|c|c|c|c|}
\hline MODELO & TÉCNICA & FORTALEZA & DEBILIDAD \\
\hline Dow Chemical, 1994. & $\begin{array}{l}\text { El valor de la organización se } \\
\text { produce por la intersección } \\
\text { de sus tres vértices, que } \\
\text { son: el capital humano, el } \\
\text { organizacional y el de las } \\
\text { relaciones. }\end{array}$ & $\begin{array}{l}\text { Primer informe de Capital } \\
\text { Intelectual para una empresa } \\
\text { de EE.UU. }\end{array}$ & $\begin{array}{l}\text { Surge centrado en el valor } \\
\text { de marca y olvida otros } \\
\text { intangibles. }\end{array}$ \\
\hline Celimi, 1995. & $\begin{array}{l}\text { Propone una auditoría } \\
\text { de conocimientos, con } \\
\text { agrupación de los activos } \\
\text { intangibles en tres categorías: } \\
\text { clientes, organización y } \\
\text { personal, intentando realizar } \\
\text { su cuantificación a partir } \\
\text { de indicadores que traten } \\
\text { de explicar tres variables: } \\
\text { crecimiento, eficiencia y } \\
\text { estabilidad. }\end{array}$ & $\begin{array}{l}\text { Nueva forma de medir los } \\
\text { intangibles, al enfocar los } \\
\text { indicadores en la explicación } \\
\text { de determinadas variables. }\end{array}$ & $\begin{array}{l}\text { La rigidez establecida en las } \\
\text { variables seleccionadas. }\end{array}$ \\
\hline $\begin{array}{l}\text { El “Technology Broker" } \\
\text { (Brooking, 1996). }\end{array}$ & $\begin{array}{l}\text { Clasifica los activos intangibles } \\
\text { en cuatro cat egorías: } \\
\text { mercado, humano, propiedad } \\
\text { intelectual e infraestructura. } \\
\text { Estandarización mediante } \\
\text { una auditoría de Capital } \\
\text { Intelectual. }\end{array}$ & $\begin{array}{l}\text { Su principal aportación es } \\
\text { la relevancia otorgada y el } \\
\text { tratamiento específico que } \\
\text { efectúa de la propiedad } \\
\text { intelectual. }\end{array}$ & $\begin{array}{l}\text { Falta de análisis cuantitativos. } \\
\text { Difícil aplicación práctica. }\end{array}$ \\
\hline \multirow[t]{3}{*}{$\begin{array}{l}\text { Navigator de Skandia } \\
\text { (Edvinsson y Malone, 1997). }\end{array}$} & \multirow{3}{*}{$\begin{array}{l}\text { Consta de cinco enfoques } \\
\text { (financiero, de clientes, } \\
\text { humano, de procesos y de } \\
\text { renovación y desarrollo) como } \\
\text { elementos del sistema de capital } \\
\text { intelectual, proponiendo para } \\
\text { cada uno de ellos un conjunto } \\
\text { de indicadores. }\end{array}$} & $\begin{array}{l}\text { Establecimiento de directrices } \\
\text { de actuación, siendo referencia } \\
\text { para muchos modelos. }\end{array}$ & $\begin{array}{l}\text { Utilización de medidas } \\
\text { financieras, porcentuales y } \\
\text { cualitativas. }\end{array}$ \\
\hline & & $\begin{array}{l}\text { Implantación real y labor de } \\
\text { difusión. }\end{array}$ & $\begin{array}{l}\text { Incapacidad de establecer } \\
\text { estrategia. }\end{array}$ \\
\hline & & & $\begin{array}{l}\text { Selección de indicadores y } \\
\text { utilidad para otras empresas. }\end{array}$ \\
\hline $\begin{array}{l}\text { Balanced Scorecard (Kaplan y } \\
\text { Norton, 1997). }\end{array}$ & $\begin{array}{l}\text { Traducción de la estrategia en } \\
\text { un conjunto de indicadores } \\
\text { financieros y no financieros } \\
\text { según } 4 \text { perspectivas } \\
\text { equilibradas: financiera, } \\
\text { de procesos, clientes y de } \\
\text { aprendizaje y crecimiento. }\end{array}$ & $\begin{array}{l}\text { Visión comprensiva de } \\
\text { medición para la gestión, } \\
\text { evitando el empleo no óptimo } \\
\text { de recursos. Incorporación de la } \\
\text { estrategia y su comunicación a } \\
\text { toda la organización, facilitando } \\
\text { la implementación. }\end{array}$ & $\begin{array}{l}\text { Rigidez en la delimitación } \\
\text { de perspectivas. Orientación } \\
\text { interna. Indirectamente se } \\
\text { utiliza para medir el Capital } \\
\text { Intelectual. }\end{array}$ \\
\hline $\begin{array}{l}\text { Modelo Intelect (1998), } \\
\text { Euroforum. Intellectus } \\
\text { (2007). }\end{array}$ & $\begin{array}{l}\text { Modelo de capital intelectual } \\
\text { que es la suma de tres bloques: } \\
\text { capital humano, estructural y } \\
\text { relacional. Estructurándose } \\
\text { en cuatro conceptos básicos: } \\
\text { componentes, elementos, } \\
\text { variables e indicadores. } \\
\end{array}$ & $\begin{array}{l}\text { El grado de consenso. Inclusión } \\
\text { del capital social y del efecto } \\
\text { multiplicador. Detalle en la } \\
\text { explicación de los elementos } \\
\text { intangibles. }\end{array}$ & $\begin{array}{l}\text { Falta una cuantificación del } \\
\text { valor de los capitales. }\end{array}$ \\
\hline $\begin{array}{l}\text { Meritum (García-Ayuso, } \\
\text { 2001). }\end{array}$ & $\begin{array}{l}\text { Separación de recursos } \\
\text { (medidos por indicadores) } \\
\text { y actividades intangibles } \\
\text { (generan procesos que revierten } \\
\text { sobre las primeras). }\end{array}$ & $\begin{array}{l}\text { Marco de referencia amplio } \\
\text { para la difusión de información } \\
\text { sobre intangibles. }\end{array}$ & $\begin{array}{l}\text { Carece de un modelo de } \\
\text { gestión propiamente dicho. }\end{array}$ \\
\hline
\end{tabular}

Fuente. Elaboración propia. 
tante es que de ahí se deriven consecuencias para la adopción de medidas en materia de política, como puede ser el hecho de por qué los aspectos relacionados con el capital intelectual no se encuentran recogidos de manera explícita, como tales, en los planes de estudios, a pesar de su importancia. De este modo, podríamos plantear, inspirados en Davenport y Prusak (1998), cómo, a través de la gestión del capital intelectual, puede obtenerse lo que se denomina 'core competences'.

Son diferentes las definiciones que se hacen del concepto de capital intelectual referidas a un país, pero tan solo se observa una diferencia de escala en relación con las utilizadas en la empresa. Sánchez Medina (2004) hace un breve repaso de estas definiciones, destacando que para Bradley (1997a) el capital intelectual de un país es la capacidad que este tiene para transformar el conocimiento y los recursos intangibles en riqueza. Edvinsson y Stenfelt (1999), por su parte, perciben el capital intelectual como el valor de las ideas generadas por la unión de capital humano y estructural, que permiten producir y compartir conocimiento. Según Malhotra (2000), la acepción se correspondería con el conjunto de activos ocultos que explican el crecimiento del país y el valor añadido de los grupos de interés.

De este modo, la extrapolación que pudiera realizarse desde el ámbito empresarial al territorial significa, en palabras de Sánchez Medina (2004), contar con los mismos componentes (humano, estructural y relacional) del capital intelectual en un mundo y otro.

Los modelos aplicados sobre capital intelectual territorial pueden agruparse en dos bloques:

- aquellos específicos de medición y gestión del capital intelectual de las naciones o regiones y

- $\quad$ los estudios de competitividad y otros estudios relacionados con el establecimiento de indicadores a nivel nacional o regional.

Entre los modelos específicos, la mayoría utiliza como modelo de referencia el Navigator de Skandia:
Rembe (1999) usa métricas para definir un plan estratégico para las generaciones futuras en Suecia: capital humano (calidad de vida, esperanza de vida, educación,...), capital de mercado (turismo, balance de servicios,...), capital de procesos (calidad de la gestión, tecnologías de la información y las comunicaciones,...) y el capital de renovación $(\mathrm{I}+\mathrm{D}$, ratio de población joven,...). Este trabajo abrió el camino para llevar a cabo otras iniciativas como las de:

- Edna Pasher \& Associated (1999), que realizó una iniciativa similar en Israel.

- Bontis (2002), para la región árabe.

- Bontis (2002), en Malaysia, analiza el capital intelectual de los sectores industriales y de servicios en dicho país. Utiliza una metodología muy particular, donde una serie de estudiantes MBA actúa como panel de expertos rellenando un cuestionario. Los resultados obtenidos permiten la configuración de algunas relaciones entre capitales con una significatividad estadística adecuada.

- Centro de Investigación sobre la sociedad del conocimiento. Rodríguez, Merino, Murcia y Villar (2004) realizan un modelo de capital intelectual para la región de Madrid partiendo del trabajo Intellectus. Distinguen cinco capitales regionales interrelacionados: capital humano, organizativo, tecnológico, social y financiero o económico, proponiéndose indicadores para cada uno de ellos.

Sobre los estudios de competitividad, destacan iniciativas relacionadas con el objetivo de estos modelos:

- El "Netherlands Benchmarking 2000", realizado por el Ministerio de Relaciones Económicas de Holanda, que tenía como objetivo un análisis de benchmarking con los países de mayor desarrollo de Holanda y poder así evaluar las condiciones económicas. Se basa en indicadores de competitividad, definiendo algunas líneas de trabajo específicas (clima macroeconómico, capital humano, 
clima de innovación infraestructura física, mercado de productos, mercado financiero), y desde este punto, clasifica indicadores para cada uno, a modo de un análisis DAFO.

- La Comisión Europea (2001) publica un documento denominado "benchmarking indicators of $\mathrm{R} \& \mathrm{D}$ nacional policies", basado en cuatro áreas temáticas en $\mathrm{I}+\mathrm{D}$ : recursos humanos, inversión pública y privada, eficiencia científica y tecnológica e impacto en la competitividad económica y el empleo, estableciendo un conjunto de veinte indicadores (cinco por área), con el fin de realizar un análisis comparativo entre los estados miembros de la Unión Europea y los referentes de Estados Unidos y Japón.

- El modelo de Ernst \& Young (1999), aplicado en Nueva Zelanda, más orientado hacia el enfoque competitivo. Presentan un total de quince indicadores relevantes para comparar los países en términos de economía del conocimiento. En este sentido, las recomendaciones permitirían establecer una mejor política pública.

- El modelo de Atkinson (2002), referido a Estados Unidos, pretende medir y estudiar las tendencias en la política económica de EEUU, con el fin de establecer las mejores vías para la adaptación a la nueva economía. Elabora un conjunto de diecisiete indicadores macroeconómicos que intentan dar una visión integral para el ajuste de la economía estadounidense al nuevo entorno.

En líneas generales, de todos ellos se puede desprender que no existe una metodología clara y un marco de referencia para la medición del capital intelectual de las naciones y/o regiones, al igual que ocurre en el ámbito empresarial.

A pesar de ello, trasladamos la propuesta del modelo que venimos aplicando en el ámbito empresarial (Nevado y López, 2002), que tiene como gran ventaja constituir una herramienta de gestión para las organizaciones, no quedando exclusivamente en la medición o valoración. Pero, además, diseñaremos un modelo integral apoyado tanto en modelos específicos como en estudios de competitividad y otros.
El tránsito al espacio regional incorpora un método para desarrollar un nuevo indicador sintético de renta perfeccionado desde los factores intangibles del espacio territorial analizado, que desarrollamos más adelante. Para ello debemos, sin duda, trasladar los cambios incluidos en el sistema de información contable de la aproximación micro a los sistemas de información de cuentas nacionales y regionales, desde la visión del capital intelectual.

En consecuencia, el trabajo que presentamos es el inicio de una línea de investigación que resulta en una necesidad y una aportación para satisfacer situaciones de comparabilidad y análisis en la sociedad del conocimiento, ya que proporciona, en su fase final, un modelo de medición y gestión del capital intelectual de los territorios que contribuye a una mejor estimación de la renta y, por ende, facilitará que las decisiones públicas y privadas, tanto de administraciones como de empresas, sean más eficientes.

\section{Notas críticas sobre relaciones de producto $y$ gasto en $\mathrm{I}+\mathrm{D}$}

La descentralización que se viene produciendo desde hace algunas décadas, demandada, a su vez, por las propias administraciones subcentrales, ha supuesto que el desarrollo regional se incardine como uno de los aspectos básicos en las iniciativas adoptadas desde diferentes instancias. No en vano, desde que a principios de la década de los setenta naciese, de manera explícita, la política regional europea, ésta se ha convertido en una política estructural para el desarrollo de muchas de las regiones que, por diferentes motivos, se han encontrado al margen de los movimientos globalizadores que se están produciendo en el ámbito internacional.

En este marco teórico, son numerosos los cambios de enfoque que han tenido lugar en los últimos años, en gran medida debido a que las economías no solo se están basando en las características físicas y tangibles con las que cuentan (recursos naturales, infraestructuras físicas), que, de manera evidente, siguen siendo fundamentales, sino que también ha adquirido un papel primordial el hecho de que las economías están 
centrando su crecimiento en el conocimiento y en la información. Aspectos estos que se convierten así en actores principales del futuro desarrollo de las regiones y que tienen que ver con la innovación $y$, por extensión, el capital intelectual con el que cuenten. Sin embargo, los avances en este campo, dependiendo de las regiones, no han sido todo lo satisfactorios que a priori se preveían.

Dadas las permanentes y continuas modificaciones que se vienen produciendo, desde una perspectiva tecnológica, en la economía internacional globalmente considerada, el asentamiento de las distintas actividades económicas productivas depende, en gran medida, del factor conocimiento. Como ponen de manifiesto Salas, Aguilar y Susunaga, haciendo referencia al Informe del Desarrollo Mundial 1999 (World Bank, 1999), donde se examina el papel del conocimiento en el desarrollo, "las economías no prosperan simplemente acumulando capital físico y habilidades humanas, sino fundamentadas en información, aprendizaje y adaptación", produciéndose así una compleja relación entre conocimiento y desarrollo, que es necesario entender y asimilar por parte de todos los agentes participantes en el proceso.

De este modo, parece evidente que no es aconsejable aplicar en el resto de los territorios, de manera indiscriminada, cualesquiera de las acciones emprendidas en otros lugares, cuyo éxito ha dependido de múltiples factores, tales como (OCDE, 1998): "la propia I+D, la dotación de recursos naturales, las ventajas en el manejo de tecnologías específicas, la educación o la diversidad de factores institucionales”. Así, Salas, Aguilar y Susunaga (2000) establecen tres asuntos que conviene tomar en consideración. Primero, el conocimiento y la inteligencia constituyen los factores básicos del sistema, erigiéndose en la clave para el acceso y apropiación de la información, que alimenta la dinámica de la innovación. Segundo, se hace imprescindible una interdependencia entre múltiples actores y recursos. Y, en tercer lugar, la economía informacional aumenta la integración entre redes regionales y globales.

Muchos son los trabajos empíricos que ratifican las diferencias entre regiones fruto de la innovación; no obstante, usualmente solo introducen análisis univariable, centrándose en medidas de la $\mathrm{I}+\mathrm{D}$ como el gasto o los ocupados de sectores de media y alta tecnología.

Tan solo de forma ilustrativa, incluimos aquí un análisis de este tipo para las diecisiete regiones españolas en 2002 ( $\mathrm{r}=17)$, alcanzando las siguientes conclusiones:

$$
\mathrm{PIB}_{\mathrm{r}}=f\left(I+D_{r}\right) \quad \text { ec. } 1 .
$$

- Existe una relación positiva entre ambas variables $\left(R^{2}=0.356\right)$, esto es, las regiones más/menos desarrolladas son más/menos intensivas en innovación y, por tanto, más/ menos competitivas.

- Podemos definir dos claros grupos de regiones, las destacadas en innovación, con valores superiores al 1\% de su PIB (Madrid, País Vasco, Cataluña y Navarra) frente al resto.

- El análisis se encuentra sesgado, la relación muestra carencias, con alta probabilidad de existencia de otras variables relevantes que expliquen el crecimiento regional. En algún caso, la relación se convierte en espuria, Islas Baleares.

La calidad de los resultados de los análisis tipo, los cambios producidos en la economía a escala mundial, las nuevas políticas de desarrollo local (regional), han motivado ya un cambio necesario en los sistemas de información contable, que engarzan con nuevos métodos más completos de medición. En este marco elaboramos el presente trabajo, con el objetivo de mejorar la visión-realización de las estrategias de desarrollo regional.

\section{La medición de intangibles: componentes e indicadores}

En la actualidad, el conocimiento del valor de los activos intangibles "ocultos" o capital intelectual que tiene una economía se convierte en elemento clave para estimar el "valor real" de la misma, esto es, no es suficiente con la cuantificación del valor de producción para estimar las diferencias en la economía del conocimiento. Entre otras razones, muchos de los factores que generan o generarán valor en dicha economía no 
son tenidos en cuenta de forma adecuada, como la innovación, factor humano, etc.

Por otra parte, al no contar con un valor exacto del importe del capital intelectual por su propia esencia, podremos, al menos, establecer estimaciones sobre la posición relativa de éste en cada región o nación, así como observar su evolución. No obstante, es necesario precisar, como analizamos anteriormente, que no existe un único modelo como alternativa; de ahí que cada organización establece los indicadores más convenientes para medir dichos capitales. Entre otros, podemos citar el porcentaje sobre producto del gasto de $\mathrm{I}+\mathrm{D}$, el empleo en sectores innovadores o algunos más elaborados en el ámbito europeo, como el índice sintético de innovación regional nacional (Regional National Summary Innovation Index. RNSII), que muestra el grado de innovación de la región respecto a su media nacional, o el índice sintético revelado de innovación regional (Revealed Regional Summary Innovation Index. RRSII), que se calcula como una media simple entre el RNSII y el índice sintético de innovación europea regional (Regional European Summary Innovation Index-REUSII).

En este sentido, recogemos la propuesta de un modelo para la medición del capital intelectual y, por ende, del potencial innovador regional, testado inicialmente en el ámbito de las organizaciones empresariales.

Bajo esta perspectiva, éste es resultado de aquellos beneficios futuros que generará una organización como consecuencia de aspectos relacionados con el capital humano y con otros estructurales (la capacidad de innovación, las relaciones con los clientes, la calidad de los procesos, productos y servicios, cultura empresarial y capital de comunicación de la empresa), que permiten aprovechar mejor las oportunidades. Dada su complejidad, difícilmente podemos explicitar todos y cada unos de sus componentes, por lo que tendremos la siguiente igualdad de partida:

$$
I C_{i}=H C_{i}+S C_{i}+N E C_{i}
$$

Donde, $I C_{i}$ es el capital intelectual de la organización i.
$H C_{i}$ es el capital humano. Recoge los conocimientos, aptitudes, motivación, formación, etc., de los trabajadores así como el sistema de remuneración y la política de contratación que posibilitan tener los efectivos adecuados para el futuro.

$S C_{i}$ es el capital estructural: Definido como el sumatorio de los capitales de procesos internos (calidad), relacional o comercial (clientes, proveedores), comunicacional (marketing) y de investigación, desarrollo e innovación (potencial tecnológico e innovador).

$N E C_{i}$ es el capital no explicitado: Aquellos capitales humanos y estructurales no incluidos en los anteriores, debido a su escasa importancia y a las restricciones de cálculo para su cuantificación, pero que, en conjunto, habría que considerar.

El capital intelectual se puede medir así mediante el establecimiento de los distintos componentes, y presentando indicadores pertinentes que sean fácilmente inteligibles, aplicables y comparables con otras empresas (sectores, territorios), mediante una estructura que permita unir el pasado, el presente y el futuro de las organizaciones, recogiendo de manera significativa la capacidad empresarial para producir beneficios sostenibles. De esta forma, recogemos una propuesta del modelo de capital intelectual que sigue la estructura analizada fundamentada en componentes e indicadores (cuadro 4). En este sentido, se presentan indicadores genéricos para medir estos capitales, que podrían ser complementados y adaptados por cada empresa en función de las actividades que caractericen su sector, pudiendo exhibir cada compañía otros índices propios de su actividad.

Los componentes del capital intelectual son, así pues, determinados mediante indicadores, que agrupamos en dos tipos:

1. Absolutos (AI). Es decir, medidos en unidades monetarias y sin relación con otra magnitud.

2. De eficiencia (EI). Son índices porcentuales que fluctúan de 0 a 1 , siendo 0 la cota que indica una situación más desfavorable y 1 , la más favorable. 
Cuadro 4. Componentes del Capital Intelectual

\begin{tabular}{|c|c|}
\hline Intangibles & Indicadores \\
\hline \multicolumn{2}{|l|}{ Capital humano (HC) } \\
\hline Sistemas de remuneración & Remuneraciones \\
\hline Sistema de contratación & Temporalidad \\
\hline Clima social & Ayudas sociales \\
\hline Formación laboral & Disfunciones laborales \\
\hline Motivación & Formación \\
\hline \multirow[t]{4}{*}{ Flexibilidad organizacional } & Satisfacción y motivación \\
\hline & Productividad \\
\hline & Rotación externa (abandonos) \\
\hline & Rotación interna (promoción) \\
\hline \multicolumn{2}{|c|}{ Capital procesos internos (PC) } \\
\hline \multirow{3}{*}{$\begin{array}{l}\text { Sistema de evaluación de calidad: procesos, productos y } \\
\text { servicios }\end{array}$} & Costes de prevención y evaluación \\
\hline & Costes de no calidad \\
\hline & Tecnologías de información \\
\hline \multicolumn{2}{|l|}{ Capital relacional o comercial (CC) } \\
\hline Cartera de clientes & Mercado \\
\hline Satisfacción y fidelidad de la cartera & Satisfacción del cliente \\
\hline Situación de la cartera de proveedores & Calidad de proveedores \\
\hline \multicolumn{2}{|l|}{ Capital comunicacional o marketing (MC) } \\
\hline $\begin{array}{l}\text { Marketing empresarial: (publicidad, promoción, relaciones } \\
\text { públicas, venta personal) }\end{array}$ & Gastos de marketing por producto \\
\hline \multirow[t]{2}{*}{ Potencial mediático contratado } & Distribución \\
\hline & Potencial mediático \\
\hline \multicolumn{2}{|c|}{ Capital de investigación, desarrollo e innovación (IDiC) } \\
\hline $\begin{array}{l}\text { Inversión en nuevas tecnologías. Inversión en nuevos productos } \\
\text { y servicios }\end{array}$ & Investigación y desarrollo \\
\hline Inversión y mejora en el sistema de información empresarial & Productividad \\
\hline \multirow[t]{2}{*}{ Capacidades o competencias } & Rotación interna (promoción) \\
\hline & Movilidad potencial \\
\hline \multicolumn{2}{|c|}{ Capital no explicitado (NEC) } \\
\hline $\begin{array}{l}\text { Activos intangibles no considerados en los anteriores } \\
\text { capitales }\end{array}$ & Indicadores no incluidos en los anteriores grupos \\
\hline
\end{tabular}

Fuente. Nevado y López (2002, p. 127-142).

En el cuadro 5 incluimos algunos de los indicadores que consideramos estándar para cuantificar el capital intelectual, si bien, en este caso, son los utilizados en un trabajo previo de los autores que sigue el enfoque mesoeconómico, usando como información la agregada obtenida por encuestas de un conjunto de empresas operativas en cierto ámbito geográfico ${ }^{1}$.

1 En Baños y otros (2005), el análisis se centra en el ámbito provincial de Castilla-La Mancha, sobre un total de 325 empresas encuestadas de una población inicial sondeada 
Cuadro 5. Indicadores para la medición del capital intelectual regional (enfoque mesoeconómico)

\begin{tabular}{|c|c|}
\hline \multicolumn{2}{|c|}{ Indicadores } \\
\hline Absolutos (AI) & De eficiencia (EI) \\
\hline \multicolumn{2}{|c|}{ Capital Humano: $\mathrm{HC}=\left(\mathrm{AI}_{\mathrm{H}} \cdot \mathrm{EI}_{\mathrm{H}}\right)$} \\
\hline \multirow[t]{2}{*}{ Inversión en formación } & Índice de sistema de promociones \\
\hline & Índice de contrataciones temporales \\
\hline \multirow[t]{3}{*}{ Masa salarial cualificada } & Índice de absentismo \\
\hline & Índice de formación adquirida por empleados \\
\hline & Índice de sugerencias aportadas \\
\hline \multicolumn{2}{|l|}{ Capital Procesos Internos: $\mathrm{PC}=\left(\mathrm{AI}_{\mathrm{P}} \cdot \mathrm{EI}_{\mathrm{P}}\right)$} \\
\hline \multirow{5}{*}{$\begin{array}{l}\text { Inversión en nueva maquinaria, prevención y protección } \\
\text { medioambiental }\end{array}$} & Índice: existe departamento de calidad \\
\hline & Índice si existe certificación de ISO \\
\hline & $\begin{array}{l}\text { Índice no existe certificación de ISO pero están en el proceso } \\
\text { previo }\end{array}$ \\
\hline & Índice sobre consecución innovaciones en procesos \\
\hline & Índice de sugerencias aportadas \\
\hline \multicolumn{2}{|c|}{ Capital Relacional o Comercial: $\mathrm{CC}=\left(\mathrm{AI}_{\mathrm{C}} \cdot \mathrm{EI}_{\mathrm{C}}\right)$} \\
\hline \multirow{3}{*}{ Trabajos realizados por otras empresas (outsourcing) } & Cuota de mercado \\
\hline & Índice utilización de comercio electrónico "ventas" \\
\hline & Índice de consecución de innovaciones en producto \\
\hline \multicolumn{2}{|c|}{ Capital Comunicacional o Marketing: $\mathrm{MC}=\left(\mathrm{AI}_{\mathrm{M}} \cdot \mathrm{EI}_{\mathrm{M}}\right)$} \\
\hline \multirow{2}{*}{ Gastos de comunicación y marketing } & Índice vendedores / empleados \\
\hline & Cuota de mercado \\
\hline \multicolumn{2}{|c|}{ Capital de Investigación, Desarrollo e Innovación: $\mathrm{IDiC}=\left(\mathrm{AI}_{\mathrm{IDi}} \cdot \mathrm{EI}_{\mathrm{IDi}}\right)$} \\
\hline & Cuota de mercado \\
\hline \multirow[t]{2}{*}{ Inversión en equipos informáticos } & Índice de formación adquirida por empleados \\
\hline & Índice ordenadores/empleados \\
\hline \multirow[t]{2}{*}{ Inversión en $\mathrm{I}+\mathrm{D}+\mathrm{i}$} & Índice de uso de PC \\
\hline & $\begin{array}{l}\text { Índices utilización de comercio electrónico: "compras" y } \\
\text { "ventas") }\end{array}$ \\
\hline
\end{tabular}

Fuente. Elaboración propia.

Es conveniente precisar que en los indicadores absolutos nos encontramos, en muchos de los casos, activos que aparecen en los balances y/o gastos contables que aparecen en las cuentas de pérdidas

de 4265, y sirvió para determinar los cambios imprescindibles en el tránsito metodológico de lo empresarial a lo regional-nacional. y ganancias. Por lo tanto, en estas ocasiones están previamente cuantificados y establecidos por las empresas. Sin embargo, lo que se pretende aquí es poner de manifiesto todo aquello que genera valor en un futuro para la organización; de ahí que sea necesario interpretarlos aplicando criterios que actualmente no figuran en las normativas contables. Es decir, la base de registro no es tanto la partida 
doble, sino las bases de datos relacionales que almacenan información (financiera y no financiera, cuantitativa y cualitativa) y la conducen a través de diferentes resultados en función de las necesidades específicas de los usuarios ${ }^{2}$.

Las aportaciones y ventajas del uso de esta metodología se centran en su cercanía, en cuanto a sistema de información, a la Nueva Economía. Es evidente que nuestras 'viejas' estadísticas necesitan cambios para ser analizadas, como lo pone de manifiesto Castells (2000) cuando analiza la evolución de la productividad en las últimas décadas del siglo XX: "...Por tanto, el cambio organizativo, la formación de una nueva fuerza de trabajo y el proceso de 'aprender haciendo', al impulsar los usos productivos de la tecnología, tendrían que acabar manifestándose en las estadísticas de productividad. A condición de que las categorías estadísticas estuvieran en condiciones de reflejar esos cambios". En este sentido, nuestra propuesta de elaborar un modelo desde un enfoque mesoeconómico intenta corregir carencias de la vieja economía. Dicho enfoque repercute en variables convencionales como la renta. Así, el desarrollo humano y estructural del tejido empresarial es correlacionado con el crecimiento económico de un área geográfica desde las perspectivas de desarrollo endógeno e identifica de manera óptima el nuevo recurso económico: el conocimiento. Por tanto, la gran ventaja es que se establece un modelo estándar que correlaciona y mide los crecimientos de renta con los niveles de capital intelectual de las zonas geográficas, permitiendo realizar comparaciones entre ellas.

Como principales inconvenientes o limitaciones del enfoque contamos con el proceso de elaboración del cuestionario, trabajo de campo y lo que conlleva en cuanto a coste y tiempo. Es decir, es necesario obtener información de las empresas a partir de una encuesta elaborada y establecer los cauces adecuados para que nos suministren la información que se necesita. Por otra parte, el propio método de generación de los componentes del capital intelectual presenta, tanto en la elaboración

2 En el ámbito nacional o regional, los sistemas contables públicos han sido derivados de los empresariales y en el método propuesto son su reflejo; en el caso de los indicadores de eficiencia son las encuestas específicas realizadas por las administraciones las que completan el modelo. de los indicadores como en el establecimiento de las distintas ecuaciones que mejor sinteticen cada uno de los componentes, algún grado de subjetividad; por ello, y para reducir al máximo la misma, deben definirse claramente las pautas de medición y valoración. También podría considerarse como limitación la extrapolación de estos resultados a efectos de una medición dentro de un escenario macroeconómico.

El método de generación de intangible intelectual (humano o estructural) se condensa en las siguientes ecuaciones.

1. Un capital (humano o estructural) estará formado por indicadores absolutos (AI) y relativos o de eficiencia (EI), con las siguientes restricciones:

$$
\mathrm{AI}_{\mathrm{X}}=\sum_{\mathrm{i}=1}^{\mathrm{N}} \mathrm{AI}_{\mathrm{iX}} \quad \text { ec. } 3 .
$$

$\mathrm{N}$ indicadores absolutos, pertenecientes al capital X (XC). X será igual a $\mathrm{H}$ : Humano, P: Procesos; C: Clientes; M: Marketing o IDi: Investigación, Desarrollo e innovación

$$
\begin{aligned}
& \mathrm{EI}_{\mathrm{X}}=\sum_{\mathrm{i}=1}^{\mathrm{k}} \mathrm{w}_{\mathrm{ji}} \mathrm{EI}_{i X} \\
& \operatorname{con} \sum w_{j}=1
\end{aligned}
$$

$\mathrm{K}$, indicadores de eficiencia pertenecientes al capital X (XC).

$\mathrm{w}$, ponderaciones que afectan a los indicadores de eficiencia, entre 0 y 1 , la suma de todas ha de ser la unidad.

El modelo multiplicativo es el que se sigue para el generador del capital X, pero un capital puede estar formado por más de un generador (ec. 5).

$$
\mathrm{XC}=\sum_{\mathrm{c}=1}^{\mathrm{m}} \mathrm{AI}_{\mathrm{cX}} \cdot \mathrm{EI}_{\mathrm{cX}}
$$

$\mathrm{m}$ generadores del capital X.

2. Los indicadores absolutos de un capital son propios del mismo y no podrán participar en la generación de otro.

3. Los indicadores de eficiencia de un capital no son exclusivos del mismo y podrán participar en la configuración de otro capital o en la del mismo afectando a otro indicador 
absoluto, esto es, participar en más de un generador de un mismo capital.

\section{Modelo macro para la medición del capital intelectual}

De acuerdo con lo expuesto anteriormente, es clara la intención de evitar formas convencionales de análisis de competitividad e innovación que siguen el enfoque macroeconómico. No obstante, dichas medidas cuentan con la ventaja de la disponibilidad de información, como, por ejemplo, es el caso, en economía local, del modelo de gestión y análisis del capital intelectual del municipio de Mataró (Viedma et al., 2004). Estos métodos introducen preferentemente medidas sobre formación e infraestructuras, a modo de cuadro de mandos que ofrecen incluso una visión dinámica al analista, con varios ejercicios de estudio, si bien esta visión se encuentra con informaciones muy dispersas que empañan el fin último del método.

Dentro de un modelo macro, una de las principales consideraciones a la que nos enfrentamos es la disponibilidad de datos homogéneos para las diferentes áreas territoriales. De ahí que conviene considerar algunas variables genéricas. Por otra parte, contamos con diferentes fuentes estadísticas, que calculan sus informaciones con distintas metodologías, haciéndolas incompatibles, factor que nos ha conducido a seleccionar las oficiales.

En este sentido, cuando se intenta implementar un modelo de estas características, debemos tener en cuenta la perspectiva de suficiencia estadística. Así, dentro de los dos componentes fundamentales del capital intelectual: humano y estructural, como vimos en el apartado anterior, debemos plantearnos las condiciones de homogeneidad y disponibilidad de información. Dentro del componente estructural, los capitales de procesos, comunicacional y comercial son muy difíciles de medir en este nivel, ya que el primero de ellos hace referencia fundamentalmente a la calidad de los procesos de las empresas e intentar agregarlo a nivel macro y que sirva como nivel de desarrollo es una tarea complicada, que precisaría, desde nuestro punto de vista, de un rediseño de las encuestas industriales y/o de comercio. Algo similar ocurre con el comunicacional y el comer- cial, que se enfocan principalmente en los clientes que ganan o pierden las compañías.

Por ello, consideramos que la medición del capital intelectual de las naciones/regiones debería circunscribirse, en este nivel, al capital humano y de $\mathrm{I}+\mathrm{D}+\mathrm{i}$ de las economías. Estos datos están disponibles, aunque sea de forma aproximativa, y responden más genéricamente a todos los agentes productivos, no solo a la empresa. En la Unión Europea, por ejemplo, se ha considerado la capacidad tecnológica como uno de los factores que determinan la riqueza y prosperidad regional, pero hay que unirlo a otros capitales. De ahí que hablemos de un capital intelectual que tiene en cuenta no solamente esta capacidad, sino también el potencial humano (capacidades, habilidades y competencias).

\section{Consideraciones técnicas}

Para realizar la implementación del método explotamos la base de datos del Instituto Nacional de Estadística español, en especial la referida a las informaciones regionales procedentes de las cuentas económicas, contabilidad regional, indicadores sociales, encuesta de población activa, de comercio, industrial y de ciencia y tecnología. Además, como complemento, se utilizaron datos procedentes del Ministerio de Educación y Ciencia.

La elección de este tipo de información ha sido motivada por su carácter oficial y tratamiento metodológico homogéneo.

Posteriormente, se estudió la base de datos de Eurostat, en su clasificación regional (NUTS II) para los países de la UE. El ejercicio de estimación ha sido el de 2002, pues era el más actual posible para el conjunto de las informaciones tratadas ${ }^{3}$. El ámbito se circunscribe a las 17 Comunidades Autónomas para España y al resto de los catorce países de la Unión en estas fechas (para Grecia no fue posible la regionalización por ausencia de información) y el método de estructura y selección de indicadores ha sido el pormenorizado en los párrafos anteriores.

En algún caso, hemos tenido que utilizar informaciones de 2001, por ejemplo, en los gastos de educación de determinados países. 


\section{Generación de los indicadores del capital intelectual}

En primer lugar, es necesario obtener un banco de datos inicial, a partir de las fuentes expuestas. En este caso, se trata de generar los indicadores absolutos y de eficiencia, que forman los distintos capitales (humano y estructural de innovación) que constituyen el capital intelectual (ec.1). Siguen el esquema siguiente:

- Humano. Diferenciamos a su vez dos perspectivas (generadores de capital): a. del coste, afectando la masa salarial por un nivel de cualificación, y b. de desarrollo, en la que se introducen los costes formativos alterados por el aprovechamiento de los mismos (integración, participación, motivación).

- Innovación: perspectiva del gasto en $\mathrm{I}+\mathrm{D}$ afectada por dos vías: a. mercado potencial donde desarrollarla, y b. penetración social de la innovación (familias, empresas).

Estas variables son recogidas por los indicadores ilustrados en el cuadro 6. En relación con los indicadores, en especial los de eficiencia en el caso humano, serían precisas más informaciones, dada la simplicidad estadística que no recoge ade- cuadamente factores de motivación, integración y aptitud laboral. El hecho ha sido inicialmente solventado con la inclusión como aproximación de la tasa de actividad referente del mercado laboral. En Europa, dichas tasas son aún bastante heterogéneas, mientras que en el norte: Finlandia, Suecia o Reino Unido, rondan el 70\%, en el sur: Grecia, Italia y España, se sitúan en torno al 50\%.

A continuación debemos trazar la estructura implementada para el cálculo de los capitales implicados como variables en el modelo. Para abordar este escollo final, es conveniente elaborar un cuadro para cada componente del capital intelectual, en el que se sintetice la ecuación utilizada con sus resultados.

Así pues, construimos una ecuación para cada capital (siguiendo la estructura de la ec. 5), donde se señale qué indicadores absolutos y de eficiencia componen el mismo. En los de eficiencia, se debe recoger además el peso que van a tener, a efectos de corregir a los absolutos.

El indicador del capital se expresará finalmente en términos relativos de VAB (producto), para posibilitar la comparabilidad entre diferentes territorios.

Cuadro 6. Indicadores para la medición del capital intelectual regional (enfoque macroeconómico)

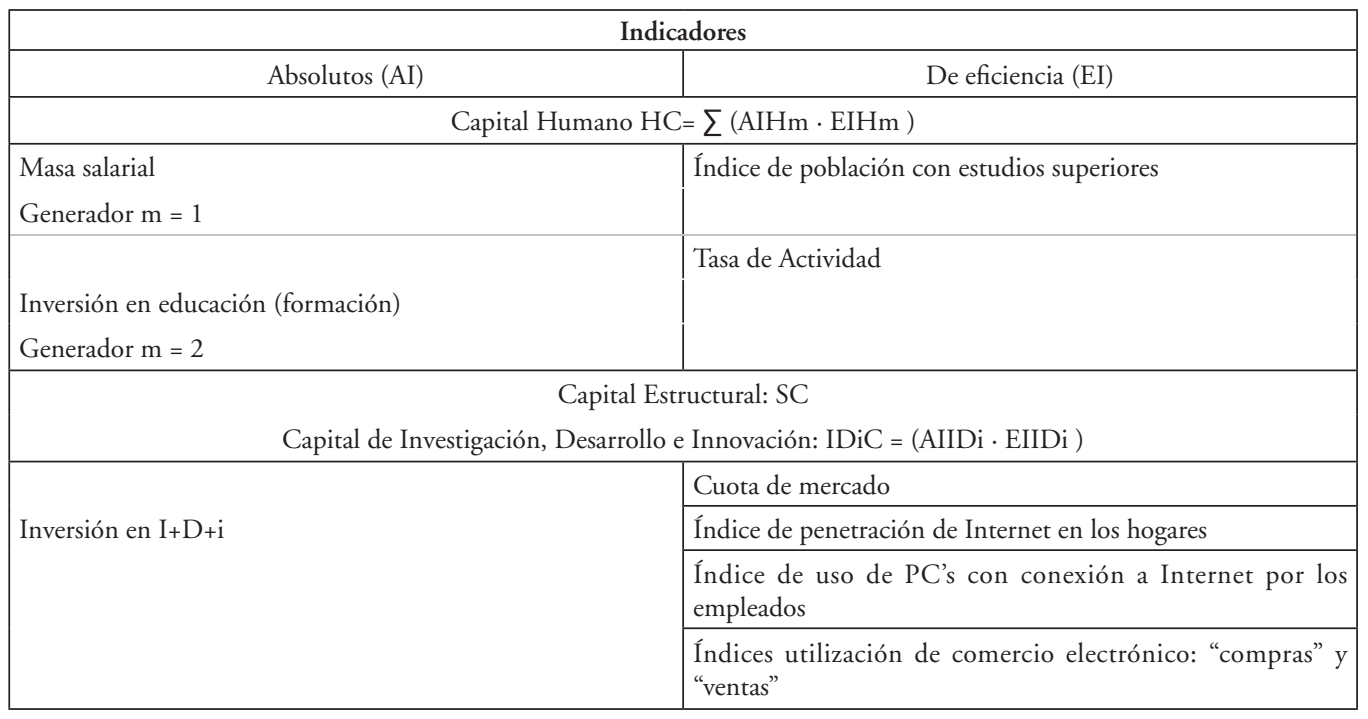

Fuente. Elaboración propia 
Víctor Raúl López Ruiz, Domingo Nevado Peña y José Baños Torres

Cuadro 7. Indicador de capital humano regional (NUTS II). Los 10 mejores de la UE15 y España.

\begin{tabular}{|c|c|c|c|c|c|c|}
\hline Región (NUTS II) / (país) & $\begin{array}{c}\text { Masa } \\
\text { salarial } \\
\text { (Mill. €) }\end{array}$ & $\begin{array}{l}\text { Ed. superior } \\
\text { / población }\end{array}$ & $\begin{array}{c}\text { Gasto en } \\
\text { educación } \\
\text { (Mill. €) }\end{array}$ & $\begin{array}{c}\text { Tasa de } \\
\text { actividad }\end{array}$ & $\begin{array}{c}\text { Indice } \\
\text { capital } \\
\text { humano }\end{array}$ & $\begin{array}{l}\text { Indice } \\
\text { capital } \\
\text { humano } \\
\text { / VAB }\end{array}$ \\
\hline Midlands Oeste (RU) & 76216,1 & $20,73 \%$ & 7158,828 & $61,60 \%$ & 20207,809 & $16,92 \%$ \\
\hline Gales (RU) & 36152,9 & $20,47 \%$ & 3889,151 & $56,20 \%$ & 9587,053 & $16,87 \%$ \\
\hline Norrland Septentrional (Sue) & 7280,8 & $17,22 \%$ & 1451,314 & $64,00 \%$ & 2182,785 & $16,76 \%$ \\
\hline Suecia Centro Oriental (Sue) & 21957,8 & $16,04 \%$ & 2368,195 & $68,50 \%$ & 5145,234 & $16,49 \%$ \\
\hline Midlands Este (RU) & 59876,3 & $20,06 \%$ & 5484,927 & $62,80 \%$ & 15457,103 & $16,43 \%$ \\
\hline Yorkshire y Humbershire (RU) & 71407,2 & $19,71 \%$ & 6480,629 & $60,50 \%$ & 17996,841 & $16,23 \%$ \\
\hline Noroeste (RU) & 95187,9 & $19,47 \%$ & 8731,616 & $59,60 \%$ & 23733,462 & $15,72 \%$ \\
\hline Escocia (RU) & 77590,1 & $19,87 \%$ & 6142,806 & $61,40 \%$ & 19186,725 & $15,69 \%$ \\
\hline Smaland e islas (Sue) & 12046,8 & $14,57 \%$ & 3253,021 & $69,50 \%$ & 4016,428 & $15,04 \%$ \\
\hline Suecia Occidental (Sue) & 28530,3 & $14,51 \%$ & 16424,378 & $72,20 \%$ & 15996,836 & $14,92 \%$ \\
\hline España & 347589 & $12,43 \%$ & 36023,200 & $53,60 \%$ & 62516,060 & $8,74 \%$ \\
\hline Extremadura & 5765,8 & $12,21 \%$ & 979,620 & $48,70 \%$ & 1181,358 & $9,46 \%$ \\
\hline Andalucia & 45991,2 & $13,33 \%$ & 7200,673 & $51,30 \%$ & 9826,850 & $9,43 \%$ \\
\hline Comunidad de Madrid & 64527,4 & $13,20 \%$ & 4903,503 & $57,40 \%$ & 11330,423 & $9,17 \%$ \\
\hline Murcia & 8146,1 & $12,56 \%$ & 1150,044 & $54,90 \%$ & 1654,545 & $9,12 \%$ \\
\hline País Vasco & 23317,2 & $12,11 \%$ & 1681,846 & $54,20 \%$ & 3735,582 & $9,09 \%$ \\
\hline Canarias & 14081,7 & $12,30 \%$ & 1625,442 & $56,30 \%$ & 2647,626 & $9,06 \%$ \\
\hline Castilla y León & 18406,6 & $13,19 \%$ & 2085,447 & $48,20 \%$ & 3433,806 & $8,73 \%$ \\
\hline Galicia & 17309,4 & $12,26 \%$ & 2163,779 & $49,80 \%$ & 3200,268 & $8,56 \%$ \\
\hline Comunidad Valenciana & 34107,5 & $11,39 \%$ & 3452,200 & $55,40 \%$ & 5797,204 & $8,48 \%$ \\
\hline Principado de Asturias & 7584,6 & $12,29 \%$ & 810,027 & $43,50 \%$ & 1284,661 & $8,38 \%$ \\
\hline Castilla-la Mancha & 11247,2 & $10,71 \%$ & 1499,926 & $49,20 \%$ & 1942,492 & $8,00 \%$ \\
\hline Cantabria & 4411,5 & $11,52 \%$ & 414,156 & $49,90 \%$ & 715,073 & $7,99 \%$ \\
\hline Aragón & 10718,8 & $11,46 \%$ & 945,453 & $50,50 \%$ & 1705,397 & $7,90 \%$ \\
\hline Navarra & 5962,5 & $10,70 \%$ & 425,632 & $55,20 \%$ & 873,225 & $7,84 \%$ \\
\hline Cataluña & 64104 & $10,44 \%$ & 5054,083 & $58,00 \%$ & 9625,975 & $7,40 \%$ \\
\hline La Rioja & 2424,2 & $10,70 \%$ & 210,942 & $51,80 \%$ & 368,757 & $7,04 \%$ \\
\hline Baleares & 7818,1 & $9,02 \%$ & 663,754 & $60,10 \%$ & 1103,887 & $6,08 \%$ \\
\hline
\end{tabular}

Fuente. Elaboración propia a partir de datos de Eurostat, INE y MEC. Ejercicio 2002.

Millones de euros. En el anexo se encuentra la síntesis de indicadores para la UE 15.

Nota: RU (Reino Unido) y Sue (Suecia).

Ecuación de capital humano (HC):

\section{$\mathrm{HC}=\left(\right.$ masa salarial ${ }^{*}$ índice educación superior $)+($ inversión en educación $*$ tasa de actividad $)$}

En el capital o intangible humano (HC) han sido recogidos principalmente dos efectos claros (generadores): por una parte, la cuantificación del factor humano, medido a través de los salarios y filtrado por el requerimiento de cualificación profesional, afectando a la masa salarial con un indicador sobre el nivel de estudios de la población en ese territorio. A tal efecto ha sido seleccionada la población con educación superior en términos porcentuales. Así, por ejemplo, para la región de Andalucía (España) 
Cuadro 8. Indicador de capital estructural de I+D+i. UE 15, 2002.

\begin{tabular}{|l|c|c|c|c|c|c|}
\hline PAÍSES UE 15 & $\begin{array}{c}\text { Gasto en I+D } \\
\text { (Mill. €) }\end{array}$ & $\begin{array}{c}\text { Gasto I+D } \\
\text { / PIB }\end{array}$ & $\begin{array}{c}\text { Hogares } \\
\text { con conexión } \\
\text { Internet (\%) }\end{array}$ & $\begin{array}{c}\text { Empleados } \\
\text { que usan } \\
\text { Internet (\%)* }\end{array}$ & $\begin{array}{c}\text { Ventas- } \\
\text { empresas por } \\
\text { Internet (\%) }\end{array}$ & $\begin{array}{c}\text { Índice IDiC / } \\
\text { PIB aproximado }\end{array}$ \\
\hline 1. Bélgica & 5115,74 & 2,24 & --- & --- & -- & $1,5955^{* *}$ \\
\hline 2. Dinamarca & 4.634 & 2,52 & 56 & 99 & 1 & 2,171 \\
\hline 3. Alemania & 53363 & 2,53 & 46 & 94 & 1 & 2,002 \\
\hline 4. Grecia & --- & --- & 12 & 82 & 0,5 & --- \\
\hline 5. España & 7193,5 & 1,03 & 17,36 & 92 & 0,3 & 0,747 \\
\hline 6. Francia & & 2,26 & 23 & --- & --- & $1,7869^{* *}$ \\
\hline 7. Irlanda & 1435 & 1,09 & --- & --- & --- & $0,8618^{* *}$ \\
\hline 8. Italia & 14.600 & 1,16 & 34 & 86 & 0,3 & 0,868 \\
\hline 9. Luxemburgo & --- & --- & 40 & 88 & 0,4 & --- \\
\hline 10. Países Bajos & 8.018 & --- & 58 & 94 & --- & 1,475 \\
\hline 11. Austria & 4684,31 & 2,15 & 33 & 96 & -- & 1,699 \\
\hline 12. Portugal & 1.029 & 0,8 & 15 & 87 & 0,6 & 0,595 \\
\hline 13. Finlandia & 4830,3 & 3,46 & 44 & 99 & 1,1 & 2,876 \\
\hline 14. Suecia & --- & --- & -- & 99 & -- & -- \\
\hline 15. Reino Unido & 31513,5 & 1,87 & 50 & 92 & 1,2 & 1,514 \\
\hline
\end{tabular}

Fuente. Elaboración propia a partir de Eurostat, INE. Ejercicio 2002.

Nota: * Empresas de más de 10 empleados. ${ }^{* *}$ Dato aproximado por interpolación.

hemos incluido cerca del $14 \%$ de los gastos de personal que se corresponden con la población con estudios superiores de la región. Por otro lado, consideramos la inversión en formación, recogida a través del gasto en educación realizado por las administraciones, necesaria para el mantenimiento y avance de dicha cualificación. En lo concerniente a los indicadores de eficiencia, ha sido seleccionada la tasa de actividad por las razones ya argüidas.

El resultado final del capital humano nos indica que las regiones con más potencial competitivo humano son las de Suecia y Reino Unido, situándose España en la parte media-baja de la UE-15. En detalle, destacan para España los valores de Madrid y País Vasco; no obstante, en términos relativos, sobresalen también las potencialidades de Extremadura y Andalucía. En síntesis, las comunidades españolas tienen un potencial endógeno de factor humano medio en relación a la UE-15 (ver cuadro 7 y anexo), destacando en las primeras posiciones el nivel de actividad y educación, lejanos a los hispanos.

Finalmente, contamos con el capital estructural en innovación calculado a partir de los gastos de I+D propiamente dichos, filtrado por la dimensión del mercado (cuota de mercado, calculada como porcentaje en el VAB de cada país) y por la dimensión de competitividad innovadora en sus perspectivas sociales y económicas (cuota de innovación como promedio de penetración de Internet en los hogares, uso de PC's con conexión a Internet por los trabajadores y utilización de comercio electrónico: "compras" y "ventas" por las empresas).

Para la estimación de este componente hemos debido utilizar diversos mecanismos correctores y de regionalización que nos han llevado a su estimación, siendo a veces imposible por la absoluta carencia informativa en Eurostat (caso de Suecia o Grecia, por ejemplo). Por estas razones, presentamos en el cuadro 8 la información inicial, recopilada por países 4 , para los indicadores implicados, que posteriormente ha sido regionalizada en términos relativos de valor añadido.

\footnotetext{
$4 \quad$ Al no disponer de información desagregada, salvo en contados casos, como se aprecia en el anexo.
} 
Víctor Raúl López Ruiz, Domingo Nevado Peña y José Baños Torres

Cuadro 9. Indicador de capital Estructural: I+D+i regional (NUTS II). Los 10 mejores de la UE15 y España.

\begin{tabular}{|l|c|}
\hline \multicolumn{1}{|c|}{ Región (NUTS II) / (país) } & IDiC \\
\hline Hamburgo (Alemania) & $3,460 \%$ \\
\hline Finlandia Meridional & $3,373 \%$ \\
\hline Bruselas Capital (Bélgica) & $3,209 \%$ \\
\hline Bremen (Alemania) & $2,756 \%$ \\
\hline Finlandia Occidental & $2,506 \%$ \\
\hline Hesse (Alemania) & $2,471 \%$ \\
\hline Finlandia Septentrional & $2,463 \%$ \\
\hline Viena (Austria) & $2,417 \%$ \\
\hline Londres (RU) & $2,382 \%$ \\
\hline Baviera (Alemania) & $2,330 \%$ \\
\hline España & $0,747 \%$ \\
\hline Comunidad de Madrid & $0,982 \%$ \\
\hline Navarra & $0,933 \%$ \\
\hline País Vasco & $0,929 \%$ \\
\hline Baleares & $0,886 \%$ \\
\hline Cataluña & $0,884 \%$ \\
\hline La Rioja & $0,827 \%$ \\
\hline Aragón & $0,786 \%$ \\
\hline Cantabria & $0,727 \%$ \\
\hline Comunidad Valenciana & $0,719 \%$ \\
\hline Canarias & $0,709 \%$ \\
\hline Castilla y León & $0,701 \%$ \\
\hline Principado de Asturias & $0,636 \%$ \\
\hline Murcia & $0,623 \%$ \\
\hline Galicia & $0,604 \%$ \\
\hline Castilla-la Mancha & $0,596 \%$ \\
\hline Andalucía & $0,565 \%$ \\
\hline Extremadura & \\
\hline
\end{tabular}

Fuente. Elaboración propia a partir de Eurostat e INE.

\section{Ecuación del capital investigación,} desarrollo e innovación (IDiC)

$\mathrm{IDiC}=$ gastos de $\mathrm{I}+\mathrm{D} *$ [cuota de mercado + ((índice de penetración de Internet en los hogares + índice uso de PC's con conexión a Internet por los empleados + índice de comercio electrónico)/3)]/2

La evolución de los índices estimados prueba que la distancia es en este factor más relevante que en el humano. Muestra un comportamiento muy positivo y distanciado en el caso de Alemania y los países escandinavos, incluida Suecia, que a pesar de no contar con la información se mueve en valores previsibles superiores a los germanos. España, en este sentido, da prueba de debilidad, alcanzando apenas una tercera parte de los índices germanos, y superando solo a Portugal y, posiblemente, a Grecia.

En lo que se refiere a las regiones españolas, destaca Madrid, le siguen Navarra, País Vasco, y Cataluña. Castilla-La Mancha y Extremadura, se sitúan a la cola, con un escaso $0,5 \%$. 
Finalmente, el agregado como capital intelectual sería la simple suma de ambos componentes humano y de innovación (ver en anexo IC). En este sentido, destacamos el mayor potencial del primero frente al segundo, tanto en términos absolutos como relativos (porcentaje del PIB), pero también la mayor relación del estructural en su capital de innovación con el crecimiento económico, como veremos a continuación.

\section{Análisis de resultados. Perspectivas de desarrollo, gestión del conocimiento}

Como corolario lógico, puede establecerse que el panorama europeo y nacional diverge territorialmente en cuanto a factores intangibles: humanos y estructurales. En los valores mínimos, destacan en la UE-15: Grecia, España y Portugal, en $\mathrm{I}+\mathrm{D}+\mathrm{i}$, países que han sido beneficiados con los recursos del Fondo de Cohesión, con el propósito de desarrollarse en el marco europeo. En esta línea se encuentran también la mayor parte de las regiones italianas.

En lo que a España se refiere, son las Comunidades (regiones) de Baleares y La Rioja las que se sitúan en los últimos lugares, sobre todo por el factor humano; en la I+D+i, destacan, por su mala posición, Extremadura, Andalucía y Castilla-La Mancha, con valores inferiores de riqueza.

En el otro extremo, son los países nórdicos y Reino Unido, en la UE-15, los que se encuentran con los indicadores más elevados. La Comunidad de Madrid y País Vasco conforman los lugares más destacados en España.

Por último, planteamos la relación de ambos factores intangibles de competitividad, en términos de PIB, con el producto per cápita de las mismas (VAB), evidenciando que tales relaciones aumentan de manera apreciable en relación con medidas utilizadas hasta ahora, como el gasto en $\mathrm{I}+\mathrm{D}$, estudiado más arriba.

De este modo, y de acuerdo con la hipótesis inicialmente establecida, las regiones más ricas son las más intensivas en capital intelectual, planteando necesariamente un escenario futuro en el que se deberá actuar si se quiere llegar a la convergencia. En factor humano, la relación es mucho más débil, como muestra la figura 1 , recogiéndose un claro efecto positivo para el caso de innovación (figura 2).

Figura 1. Relación Producto (VAB) con HC

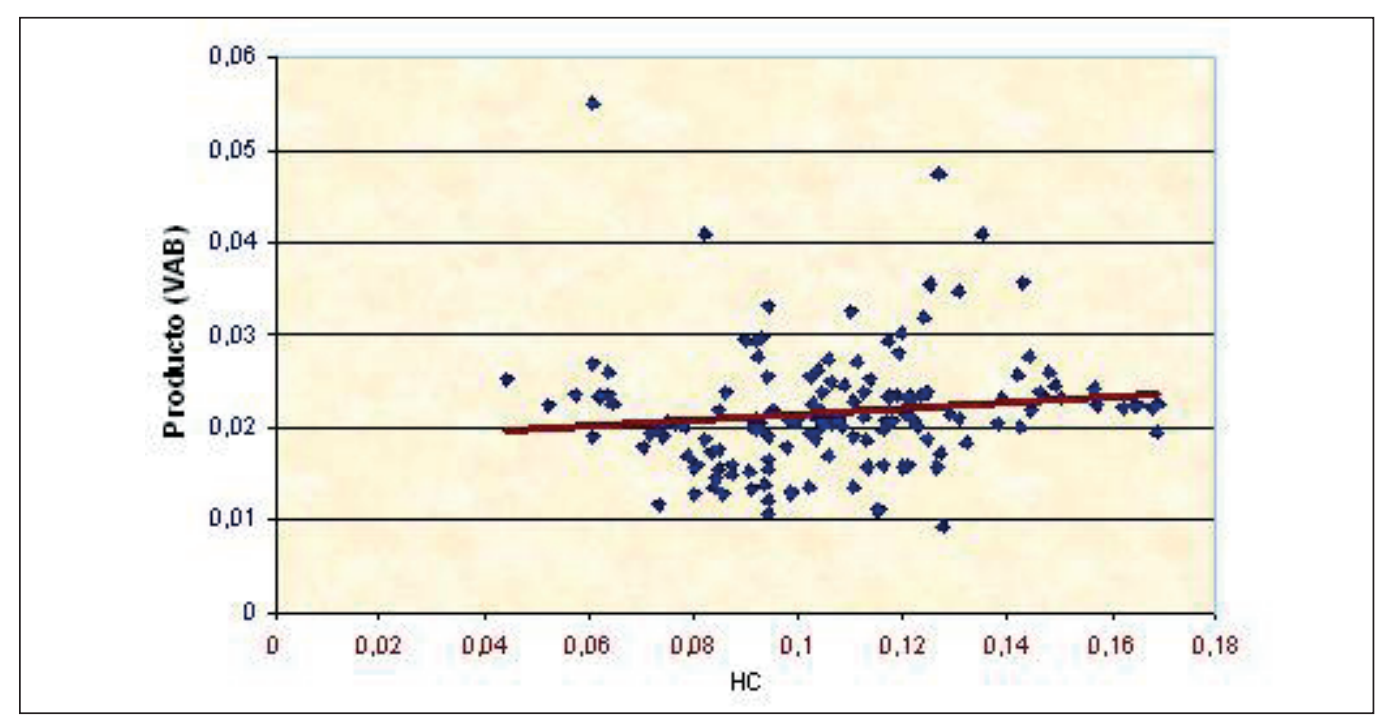

Fuente. Elaboración propia. 
Figura 2. Relación Producto (VAB) con IDiC

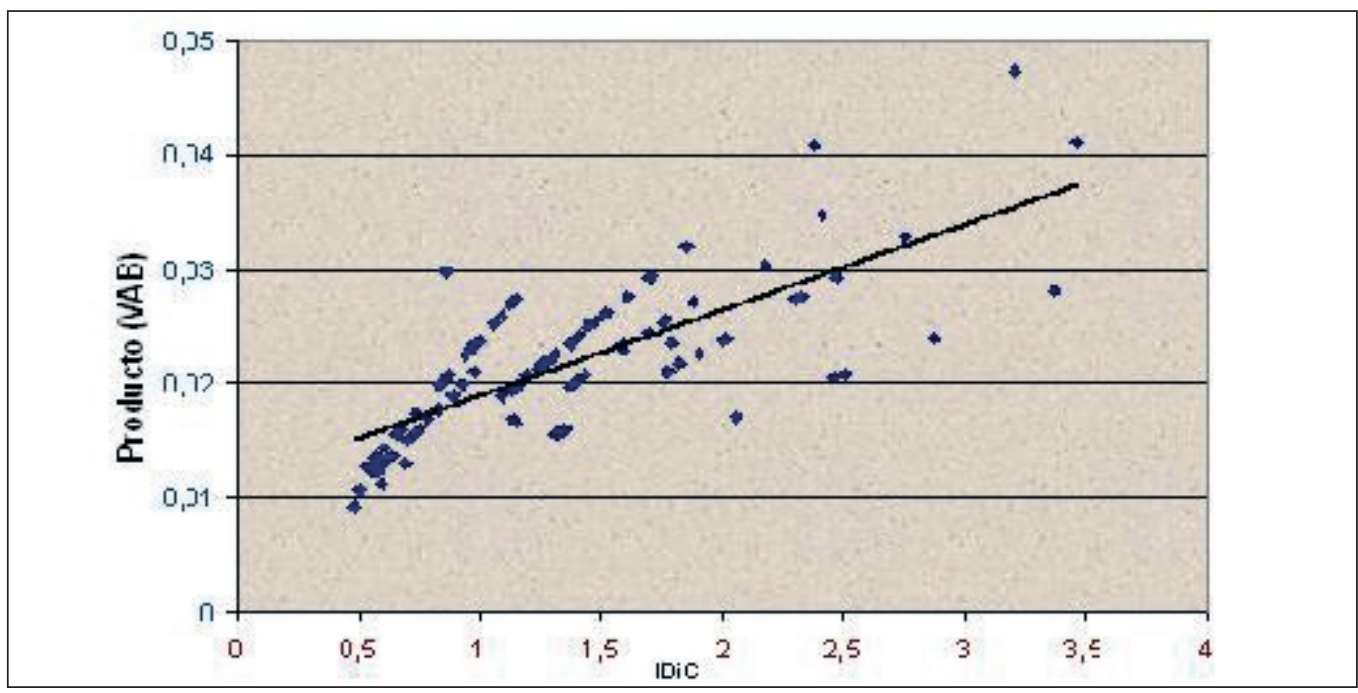

Fuente. Elaboración propia.

Como líneas futuras de investigación, más allá de este documento, podemos enumerar las siguientes:

- La falta de información, en términos agregados, sobre aspectos de capacidades de los recursos humanos y competitividad empresarial regional, por lo que tendrán que adecuarse a dichas necesidades los sistemas de información actuales como ya lo están haciendo en diversos temas como la innovación.
- La necesidad de dinamización del análisis.

- El tratamiento conjunto de los factores como explicación del desarrollo regional, sobre el que ya venimos realizando alguna medición con resultados satisfactorios (en este caso, a través del VAB per cápita). En concreto, en este análisis hemos obtenido la siguiente ecuación para 98 entidades territoriales (regiones NUTS II):

$$
\begin{gathered}
\qquad \mathrm{VAB}_{\mathrm{PC} \mathrm{i}}=0.010 * \mathrm{IDiC}_{\mathrm{i}}+0.0718 * \mathrm{HC}_{\mathrm{i}}+0.0118 * \mathrm{~F}_{\mathrm{i}} \\
\left(\begin{array}{c}
(13.95) \\
\mathrm{R}^{2}=0.578
\end{array}\right. \\
{ }^{\dagger} \text { Valores de estadístico t entre paréntesis, } \\
\text { F variable ficticia para } 7 \text { regiones: Bruselas, Londres, Irlanda(2), Finlandia(3). }
\end{gathered}
$$

- La reflexión necesaria que ha de llevarse a cabo en lo que a la participación en los Programas Marco de I+D se refiere, así como la influencia de esta política europea en la convergencia entre Estados miembros y regiones europeas.

En definitiva, la inclusión del enfoque del conocimiento en el análisis regional aporta un factor, hasta ahora no considerado, que forma parte de la función de producción que explicaría de modo más adecuado la divergencia real entre regiones. Ello significaría que las actuaciones en materia de innovación no solo deberían incrementarse, sino que además habrían de adecuarse a la situación concreta de cada uno de los territorios. No obstante, no todo es inversión en $\mathrm{I}+\mathrm{D}$, ni tan siquiera lo más importante; debemos conjugar estas políticas con otras tan necesarias o más que aquellas, como formación, actitud ante el trabajo, motivación, integración, expansión de mercados, 
cultura de innovación, relaciones en el trabajo, entre otras. Son estas cuestiones para las cuales se exige un cambio de mentalidad, de cultura empresarial, etc.

La implementación de este tipo de actuaciones, medidas y, con carácter genérico, políticas estratégicas, debe contar con la coordinación del conjunto de los diferentes niveles de administración que actualmente existen.

Sin embargo, se plantean cuestiones que aún hoy no tienen una contestación única, entre las que se pueden citar las siguientes: ¿con qué criterios han de distribuirse los recursos existentes, cuyo objetivo se centra en la modernización del sistema, al tiempo que en la reducción de los diferenciales de renta y riqueza?, ¿deben ser los territorios (regiones) 'ricos', por otro lado, más eficientes, los que obtengan una mayor participación en los denominados 'fondos tecnológicos' provenientes de la UE o, por el contrario, esos mismos fondos deben servir de soporte para intentar contribuir a la reducción de las diferencias entre regiones?. Por otro lado, ¿cómo incentivar que las empresas dediquen más recursos a los componentes que forman parte de estos intangibles?, ¿a partir de variables fiscales? En este sentido, recientemente se ha propuesto cierta armonización fiscal, en el entorno europeo, a partir de la creación de una "base fiscal común corporativa consolidada", lo que significaría cierta imposibilidad de utilizar la fiscalidad como instrumento para el crecimiento y el desarrollo económico, tal como en su momento desarrolló Irlanda.

En definitiva, las soluciones no son únicas, ni fáciles de compatibilizar, lo que no significa que deba existir una actitud pasiva ante los grandes y continuos movimientos que se vienen produciendo en un mundo cada vez más globalizado.

\section{Referencias bibliográficas}

Amidon, D.M. (2001). The intellectual capital of nations. Recuperado en julio de 2002, de http://www.entovation.com/whatsnew/icnations.htm.

Atkinson (2002). The 2002 state new economy index: benchmarking economic transformation in the states. The Progressive Policy Institute.
Baños, J.; López, V.R.; Nevado, D. \& Sanz, Ma.M. (2005). Estrategias de desarrollo local para los municipios de Castilla-La Mancha. Albacete: Popular Libros.

Bontis, N. (2002). National intellectual capital index: intellectual capital development in the Arab Region. New Cork: United Nations Office for Project Services.

Bontis, N; Chua, W. \& Richardson, S. (2002). Intellectual capital and the nature of business in Malaysia. Journal of Intellectual Capital, 1 , 1, 85-100.

Bradley, K. (1997a). Intellectual capital and the new wealth of nations. Business Strategy Review, $8,1,53-62$.

(1997b). Intellectual capital and the new wealth of nations II. Business Strategy Review, 8, 4, 33-44.

Brooking, A. (1997). El capital intelectual. El principal activo de las empresas del tercer milenio. Barcelona: Paidós.

Bueno, E. (1999). Gestión del conocimiento, aprendizaje y capital intelectual. Boletín del Club Intelect, 1.

(2002). El capital social en el nuevo enfoque del capital intelectual de las organizaciones. Revista de psicología del trabajo y de las organizaciones, 18, 2-3, 157-176.

Camisón, C.; Palacios, D. \& Devece, C. (2000). Modelo NOVA. Recuperado el 1 de julio de 2002, de http://www.gestióndelconocimiento.com.

Cañibano Calvo, L. (2001). Contabilidad e información sobre intangibles: una necesidad apremiante. Especial XI Congreso AECA.

Castells, M. (2000). La era de la información. La sociedad red. Madrid: Alianza Editorial.

Castilla, F. (2006). La gestión de intangibles en el sector del aceite de oliva. Tesis Doctoral. Jaén.

Clairesse, B. \& Muldur, U. (2001). Regional cohesion in Europe? An analysis of how EU public RTD support influences the techno-economic landscape. Research Policy, 30, 275-296.

Correa, M.D.; Fanlo, A.; Manzanedo, J. \& Santillán, S. (1995). Fondos comunitarios en España: regionalización y análisis de incidencia. Madrid: Ministerio de Economía y Hacienda, Dirección General de Planificación. D-95002.

Dalmau, J.I. \& Baixauli, J.J. (2005). Modelo para la gestión de capital intelectual de una región: una aproximación. Ponencia presentada en el 
tercer Congreso Internacional Gestión del Conocimiento y de la Calidad, Bogotá.

Davenport, T.H. \& Prusak, L. (1998). Working knowledge. Boston: Harvard Business School Press.

Duth Ministry of Economic Affairs (2000). Benchmarking the Netherlands 2000. On the threshold of the new millenium. The Hague: Ministry of Economic Affaire.

Edvinsson, L. \& Malone, M. S. (1999). El capital intelectual. Cómo identificar y calcular el valor de los recursos intangibles de su empresa. Barcelona: Gestión 2000.

Edvinsson, L. \& Stenfelt, C. (1999). Intellectual capital of nations for future wealth creation. Journal of Human Resource Costing and Accounting, 4, 1, 21-33.

Elektronisk version ved net bureauet (1998). Intellectual capital accounts. Udgivet af EFS $i$ maj.

Ernst \& Young New Zealand (1999). The knowledge economy. A, submission to the New Zealand Government by the Minister for Information Technology's IT Advisory Group. August.

Euroforum ESCORIAL (1998). Medición del capital intelectual: modelo Intelect. Madrid: Euroforum Escorial

European Comission (1997). Cohésion, recherche, compétitivité: exploiter les synergies entre politique RDT et d'innovation et politique de cohésion économique et sociale. Brussels. (EC, 2002a). Cuadro de indicadores de innovación de 2002. SEC regions.

(EC, 2002b). European innovation scoreboard: Technical Paper. No 3. EU regions.

Eustace, C. (2001). The intangible economy-impacts and policy issues. Luxemburgo: European Commission's HLEG.

Fagerberg, J. \& Verspagen, B. (1994). Heading for divergent? Regional growth in Europe reconsidered. Journal of Common Market Studies, 34, 3, 431-448.

Fundación Cotec para la innovación tecnológica (2001). Informe COTEC, Tecnología e Innovación en España.
García-Ayuso, M. (2001). Meritum project's: guidelines for managing and reporting on intangibles. Ponencia presentada en International research seminar intangibles and intellectual capital: emerging issues in company valuation, reporting and management, Ferrara.

Grupo de investigación Intelectus (2007). Foro Intellectus. Recuperado de www.iade.org

Kaplan, R.S. \& Norton, D.P (1997). Cuadro de mando integral. Barcelona: Gestión 2000.

(2001). The strategy focused organisation. Boston: Harvard Business School Press.

Lev, B. (2001). Intangibles, management measurement and reporting. Washington DC: Brookings Institute Press

López, V.R. \& Nevado, D. (2006). Gestione y controle el valor integral de su empresa. Madrid: Diaz de Santos.

Lusch, R.F. \& Harvey, M.G. (1994). The case for an off-balance-sheet controller. Sloan Management Review. Winter.

Malhotra, Y. (2000). Knowledge assets in the global economy: assessment of nacional intellectual capital. Journal of Global Information Management, 8, 3, 5-15.

Ministerio de Administraciones Públicas, MAP (2002). Libro Blanco para la mejora de los servicios públicos. Recuperado el 1 de enero de 2003 de http://www.map.es/libro.htm.

Nevado, D. \& López, V. R. (2002). El capital intelectual: valoración y medición. Madrid: Prentice-Hall.

OCDE (2005). Ciencia, tecnología e industria: indicadores de la OCDE.

Pellegrín, J.P. (1991). Le rôle des organismes intermédiaires dans le dévelopment territoria. Mimeo, OCDE. Programa ILE, Paris.

Proyecto Meritum (2002). Directrices para la gestión y difusión de información sobre intangibles. Madrid: Fundación Airtel Móvil.

Quinn, J.B. (1992). Intelligent enterprise: a knowledge and service based. Free Press.

Rembe, A. (1999). Invest in Sweden: report 1999. Stockholm, Sweden: Halls FOCET AB.

Robertson, R. (2000). Globalización: tiempo-espacio y homogeneidad-heterogeneidad. Zona abierta, 92-93, 213-242. 
Rodríguez, J.L. (2004). Propuesta de creación de un Modelo de Capital Intelectual para el sector hotelero español, mexicano, chileno y dominicano. Centro de Estudios de América Latina y el Banco Santander Central Hispano. Enerodiciembre.

Rodríguez, J., Merino, C., Murcia, C. \& Villar, L. (2004). Hacia un modelo regional de capital intelectual: el caso de la región de Madrid. Ponencia presentada en el congreso de AECA.

Roos, J., Dragonetti, N.C., Roos, G. \& Edvenisson, L. (2001). Capital intelectual. El valor intangible de las empresas. Barcelona: Paidós Empresa.

Salas, C.P., Aguilar, I. \& Susunaga, G. (2000). El papel de la innovación en el desarrollo económico regional: Algunas lecciones y experiencias del contexto internacional. Transferencia 13, 49. Recuperado en enero de 2000 de http:// www.mty.itesm.mx/die/ddre/transferencia/ Transferencia49/eli-01.thm.

Sánchez, A.J. (2004). Desarrollo sostenible y capital intellectual de un territorio. Contribuciones a la Economía. Recuperado en septiembre de 2004, de http://www.eumed.net/ce.

Sveiby, K.E. (1997). The intangible assets monitor. Journal of Human Resource Costing \& Accounting, 2, 1.
Tjänesteförbundet tjänesteforetagens värden (1993). Rekommendationer om styrtal i tjänesteföretag Stockholm, Tjänesteförbundet.

Vázquez Barquero, A. (1999). Desarrollo, redes e innovación. Lecciones sobre desarrollo endógeno. Madrid: Ediciones Pirámide.

Vázquez Barquero, A. \& Sáez Cala, A. (1997). La transformación de los sistemas productivos locales y la globalización. Revista Valenciana d'Éstudis Autonomics, 19, 37-58.

Vence Deza, X. (1995). Economía de la innovación $y$ del cambio tecnológico. Madrid: Siglo XXI de España editores.

Vickery, G. (2000). Accounting for intangibles. En P. Buigues, T. Jacquemin \& D. Marchipont, Competitiveness and the value of intangible (pp. 72-101), Edward Elgar, Cheltenham.

Viedma, J.M., López, M.A., Subirats, X. \& Marín, J. (2004). La gestión del capital intelectual en Mataró (GCIM). En Medición, control y gestión de los intangibles (pp. 201-226). Barcelona: Deusto y ACCID.

World Bank (1999). World development report 1998/99. New York: Oxford University Press.

Zambon, S. (2003). Study on the measurement of intangible assets and associated reporting practices. Brussels: European Commission. 
Víctor Raúl López Ruiz, Domingo Nevado Peña y José Baños Torres

Anexo. Indicadores sintéticos de capital intelectual (IC): factor humano (HC) y estructural (I+D+iC). UE 15. Ejercicio 2002.

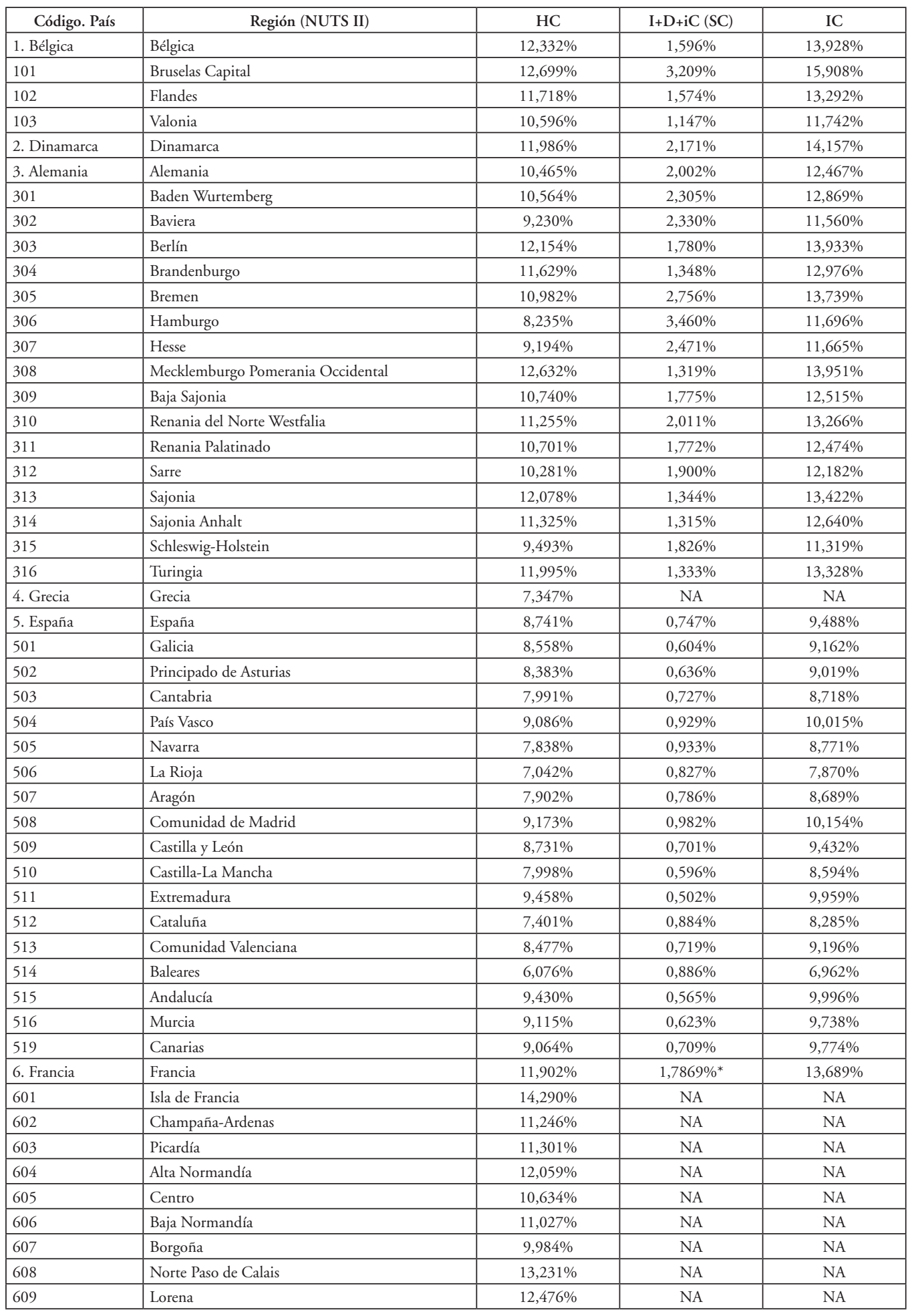


Indicador sintético de capital intelectual: humano y estructural. Un factor de competitividad

\begin{tabular}{|c|c|c|c|c|}
\hline 610 & Alsacia & $12,125 \%$ & NA & NA \\
\hline 611 & Franco Condado & $12,278 \%$ & NA & NA \\
\hline 612 & Países del Loira & $11,792 \%$ & NA & NA \\
\hline 613 & Bretaña & $11,643 \%$ & NA & NA \\
\hline 614 & Poitou- Charentes & $10,340 \%$ & NA & NA \\
\hline 615 & Aquitania & $9,827 \%$ & NA & NA \\
\hline 616 & Mediodía Pirineos & $10,827 \%$ & NA & NA \\
\hline 617 & Lemosin & $9,443 \%$ & NA & NA \\
\hline 618 & Ródano Alpes & $12,129 \%$ & NA & NA \\
\hline 619 & Auvernia & $10,238 \%$ & NA & NA \\
\hline 620 & Languedoc- Rosellón & $9,796 \%$ & NA & NA \\
\hline 621 & Provenza- Alpes-Costa Azul & $10,341 \%$ & NA & NA \\
\hline 622 & Córcega & $8,483 \%$ & NA & NA \\
\hline 7. Irlanda & Irlanda & $9,322 \%$ & $0,8618 \% *$ & $10,184 \%$ \\
\hline 701 & Centro-Oeste & $9,263 \%$ & NA & NA \\
\hline 702 & Sur-Este & $9,428 \%$ & NA & NA \\
\hline 8. Italia & Italia & $7,499 \%$ & $0,868 \%$ & $8,367 \%$ \\
\hline 801 & Piamonte & $5,720 \%$ & $0,994 \%$ & $6,714 \%$ \\
\hline 802 & Valle de Aosta & $4,411 \%$ & $1,060 \%$ & $5,471 \%$ \\
\hline 803 & Liguria & $5,215 \%$ & $0,939 \%$ & $6,154 \%$ \\
\hline 804 & Lombardía & $6,055 \%$ & $1,130 \%$ & $7,185 \%$ \\
\hline 805 y 806 & Alto Trentino y Tilor meridional & NA & $1,148 \%$ & NA \\
\hline 807 & Véneto & $6,181 \%$ & $0,983 \%$ & $7,164 \%$ \\
\hline 808 & Friul Venecia Julia & $6,359 \%$ & $0,988 \%$ & $7,348 \%$ \\
\hline 809 & Emilia Romaña & $6,376 \%$ & $1,088 \%$ & $7,464 \%$ \\
\hline 810 & Toscana & $6,432 \%$ & $0,952 \%$ & $7,384 \%$ \\
\hline 811 & Umbria & $7,365 \%$ & $0,839 \%$ & $8,204 \%$ \\
\hline 812 & Las Marcas & $7,677 \%$ & $0,855 \%$ & $8,533 \%$ \\
\hline 813 & Lacio & $8,581 \%$ & $0,995 \%$ & $9,576 \%$ \\
\hline 814 & Abruzos & $8,363 \%$ & $0,731 \%$ & $9,094 \%$ \\
\hline 815 & Molise & $8,050 \%$ & $0,670 \%$ & $8,720 \%$ \\
\hline 816 & Campania & $11,058 \%$ & $0,572 \%$ & $11,629 \%$ \\
\hline 817 & Apulia & $9,359 \%$ & $0,575 \%$ & $9,934 \%$ \\
\hline 818 & Basilicata & $8,411 \%$ & $0,606 \%$ & $9,017 \%$ \\
\hline 819 & Calabria & $9,865 \%$ & $0,537 \%$ & $10,402 \%$ \\
\hline 820 & Sicilia & $10,208 \%$ & $0,566 \%$ & $10,774 \%$ \\
\hline 821 & Cerdeña & $9,453 \%$ & $0,654 \%$ & $10,107 \%$ \\
\hline 9. Luxemburgo & Luxemburgo & $6,061 \%$ & NA & NA \\
\hline 10. Países Bajos & Países Bajos & $10,244 \%$ & $1,475 \%$ & $11,719 \%$ \\
\hline 1001 & Groninga & $11,740 \%$ & $1,694 \%$ & $13,433 \%$ \\
\hline 1002 & Frisia & $10,485 \%$ & $1,196 \%$ & $11,681 \%$ \\
\hline 1003 & Drente & $7,169 \%$ & $1,118 \%$ & $8,287 \%$ \\
\hline 1004 & Overijssel & $12,910 \%$ & $1,236 \%$ & $14,145 \%$ \\
\hline 1005 & Güeldres & $10,454 \%$ & $1,257 \%$ & $11,710 \%$ \\
\hline 1006 & Flevoland & $8,225 \%$ & $1,092 \%$ & $9,317 \%$ \\
\hline 1007 & Utrecht & $12,393 \%$ & $1,851 \%$ & $14,244 \%$ \\
\hline 1008 & Holanda Septentrional & $8,972 \%$ & $1,704 \%$ & $10,676 \%$ \\
\hline 1009 & Holanda Meridional & $10,375 \%$ & $1,520 \%$ & $11,895 \%$ \\
\hline 1010 & Zelanda & $8,475 \%$ & $1,262 \%$ & $9,737 \%$ \\
\hline 1011 & Brabante Septentrional & $10,604 \%$ & $1,442 \%$ & $12,046 \%$ \\
\hline 1012 & Limburgo & $9,537 \%$ & $1,271 \%$ & $10,809 \%$ \\
\hline 11. Austria & Austria & $10,873 \%$ & $1,699 \%$ & $12,571 \%$ \\
\hline 1101 & Burgenland & $9,429 \%$ & $1,148 \%$ & $10,577 \%$ \\
\hline 1102 & Baja Austria & $9,175 \%$ & $1,375 \%$ & $10,550 \%$ \\
\hline 1103 & Viena & $13,063 \%$ & $2,417 \%$ & $15,479 \%$ \\
\hline
\end{tabular}


Víctor Raúl López Ruiz, Domingo Nevado Peña y José Baños Torres

\begin{tabular}{|c|c|c|c|c|}
\hline 1104 & Carintia & $10,443 \%$ & $1,401 \%$ & $11,844 \%$ \\
\hline 1105 & Estiria & $11,660 \%$ & $1,435 \%$ & $13,095 \%$ \\
\hline 1106 & Alta Austria & $11,057 \%$ & $1,591 \%$ & $12,648 \%$ \\
\hline 1107 & Salzburgo & $11,116 \%$ & $1,880 \%$ & $12,996 \%$ \\
\hline 1108 & Tirol & $11,396 \%$ & $1,755 \%$ & $13,150 \%$ \\
\hline 1109 & Vorarlberg & $9,405 \%$ & $1,771 \%$ & $11,175 \%$ \\
\hline 12. Portugal & Portugal & $11,511 \%$ & $0,595 \%$ & $12,106 \%$ \\
\hline 1201 & Continente & $11,531 \%$ & $0,594 \%$ & $12,124 \%$ \\
\hline 1202 & Región Autónoma de Azores & $12,759 \%$ & $0,487 \%$ & $13,247 \%$ \\
\hline 1203 & Región Autónoma de Madeira & $9,868 \%$ & $0,691 \%$ & $10,559 \%$ \\
\hline 13. Finlandia & Finlandia & $12,457 \%$ & $2,876 \%$ & $15,334 \%$ \\
\hline 1301 & Finlandia Oriental & $12,733 \%$ & $2,059 \%$ & $14,792 \%$ \\
\hline 1302 & Finlandia Meridional & $11,946 \%$ & $3,373 \%$ & $15,318 \%$ \\
\hline 1303 & Finlandia Occidental & $13,050 \%$ & $2,506 \%$ & $15,556 \%$ \\
\hline 1304 & Finlandia Septentrional & $13,823 \%$ & $2,463 \%$ & $16,287 \%$ \\
\hline 1305 & Aland & NA & NA & NA \\
\hline 14. Suecia & Suecia & $14,189 \%$ & NA & NA \\
\hline 1001 & Estocolmo & $12,509 \%$ & NA & NA \\
\hline 1402 & Suecia Centro Oriental & $16,486 \%$ & NA & NA \\
\hline 1403 & Suecia Meridional & $14,649 \%$ & NA & NA \\
\hline 1404 & Suecia Centro Septentrional & $14,441 \%$ & NA & NA \\
\hline 1405 & Norrland Central & $13,905 \%$ & NA & NA \\
\hline 1406 & Norrland Septentrional & $16,765 \%$ & NA & NA \\
\hline 1407 & Smaland e islas & $15,035 \%$ & NA & NA \\
\hline 1408 & Suecia Occidental & $14,924 \%$ & NA & NA \\
\hline 15. Reino Unido & Reino Unido & $14,779 \%$ & $1,514 \%$ & $16,293 \%$ \\
\hline 1501 & Nordeste & $9,281 \%$ & $1,153 \%$ & $10,434 \%$ \\
\hline 1502 & Noroeste & $15,718 \%$ & $1,300 \%$ & $17,018 \%$ \\
\hline 1503 & Yorkshire y Humbershire & $16,227 \%$ & $1,298 \%$ & $17,525 \%$ \\
\hline 1504 & Midlands Este & $16,433 \%$ & $1,301 \%$ & $17,734 \%$ \\
\hline 1505 & Midlands Oeste & $16,919 \%$ & $1,313 \%$ & $18,232 \%$ \\
\hline 1506 & Este & $12,435 \%$ & $1,384 \%$ & $13,819 \%$ \\
\hline 1507 & Londres & $13,553 \%$ & $2,382 \%$ & $15,935 \%$ \\
\hline 1508 & Sureste & $14,420 \%$ & $1,609 \%$ & $16,030 \%$ \\
\hline 1509 & Suroeste & $14,677 \%$ & $1,369 \%$ & $16,046 \%$ \\
\hline 1510 & Gales & $16,874 \%$ & $1,135 \%$ & $18,009 \%$ \\
\hline 1511 & Escocia & $15,691 \%$ & $1,410 \%$ & $17,102 \%$ \\
\hline 1512 & Irlanda del Norte & $14,242 \%$ & $1,163 \%$ & $15,405 \%$ \\
\hline
\end{tabular}

Fuente. Elaboración propia a partir de los datos de Eurostat e INE.

Notas: NA: No hay datos o no es posible su cálculo. En el caso de Grecia, no ha sido posible la regionalización de factores. 